\title{
Thermodynamic equilibrium at heterogeneous pressure
}

\author{
J. C. Vrijmoed ${ }^{1,2} \cdot$ Y. Y. Podladchikov ${ }^{1}$
}

Received: 19 November 2014 / Accepted: 11 June 2015 / Published online: 15 July 2015

(C) Springer-Verlag Berlin Heidelberg 2015

\begin{abstract}
Recent advances in metamorphic petrology point out the importance of grain-scale pressure variations in high-temperature metamorphic rocks. Pressure derived from chemical zonation using unconventional geobarometry based on equal chemical potentials fits mechanically feasible pressure variations. Here, a thermodynamic equilibrium method is presented that predicts chemical zoning as a result of pressure variations by Gibbs energy minimization. Equilibrium thermodynamic prediction of the chemical zoning in the case of pressure heterogeneity is done by constrained Gibbs minimization using linear programming techniques. In addition to constraining the system composition, a certain proportion of the system is constrained at a specified pressure. Input pressure variations need to be discretized, and each discrete pressure defines an additional constraint for the minimization. The Gibbs minimization method provides identical results to a geobarometry approach based on chemical potentials, thus validating the inferred pressure gradient. The thermodynamic consistency of the calculation is supported by the similar result obtained from two different approaches. In addition,
\end{abstract}

Communicated by Othmar Müntener.

Electronic supplementary material The online version of this article (doi:10.1007/s00410-015-1156-1) contains supplementary material, which is available to authorized users.

J. C. Vrijmoed

johannes.vrijmoed@erdw.ethz.ch

1 Institute of Earth Sciences, UNIL, Quartier UNIL-Mouline, Bâtiment Géopolis, 1015 Lausanne, Switzerland

2 Present Address: Department of Earth Sciences, Institute of Geochemistry and Petrology, ETH Zurich, Clausiusstrasse 25, 8092 Zurich, Switzerland the method can be used for multi-component, multi-phase systems of which several applications are given. A good fit to natural observations in multi-phase, multi-component systems demonstrates the possibility to explain phase assemblages and zoning by spatial pressure variations at equilibrium as an alternative to pressure variation in time due to disequilibrium.

Keywords Equilibrium thermodynamics $\cdot$ Non-lithostatic pressure $\cdot$ Pressure variations - Constrained Gibbs energy minimization $\cdot$ Phase equilibria $\cdot$ Compositional zoning

\section{Introduction}

The existence of grain-scale pressure heterogeneity during metamorphism has been established over the last decades (see review in Moulas et al. 2013). In petrology, a wellstudied example is the preservation of coesite or diamond inclusions in a host mineral such as garnet (Chopin 1984), omphacite (Smith 1984) or zircon (Carswell et al. 2003). The host mineral prevents the coesite from transforming into the lower-density quartz structure (Gillet et al. 1984; van der Molen and van Roermund 1986; Zhang 1998a; Ye et al. 2001; Barron 2005; O'Brien and Ziemann 2008). The coesite inclusion then can be transformed only partially to quartz. The kinetics of the transformation from coesite to quartz was experimentally studied (Mosenfelder and Bohlen 1997; Perrillat et al. 2003), and these experiments show that at temperatures above $450{ }^{\circ} \mathrm{C}$ the coesite to quartz reaction will proceed to completion within a few hours. Therefore, the P-T conditions of the inclusion stay on the coesite-quartz equilibrium line which is the only place where quartz and coesite coexist and do not follow the $\mathrm{P}-\mathrm{T}$ path of the host mineral or matrix assemblage. 
Such a mechanism is also known as the pressure vessel effect (Chopin 2003). As a result, we know that host minerals such as garnet, clinopyroxene, zircon and diamond can sustain significant pressure variations of up to several GPa difference.

Elastic models provided a solution to the inclusion-host problem where the inclusion remained at its high pressure while pressure in the host adapted to the matrix pressure (Gillet et al. 1984; van der Molen and van Roermund 1986). Later, mechanical models adopted viscoelastic solutions in which pressure gradually decreased from the inclusion into the host (Zhang 1998a). Recently, Tajčmanová et al. (2014) used an elastic-plastic solution to expand the mechanical feasibility of maintaining pressure variations to polycrystalline materials or radially cracked inclusions.

Theoretically predicted and inferred large pressure variations were also proved by in situ measurements in coesite inclusions using Raman spectroscopy (Parkinson and Katayama 1999; Parkinson 2000). The use of Raman methods has revolutionized consideration of the overpressures developed in inclusions (Guiraud and Powell 2006). These methods allowed present-day overpressures to be deduced via the experimentally determined shift of peaks in Raman spectra. With recent developments of Raman spectroscopy and calibration for pressure with Raman shift (Schmidt and Ziemann 2000), it has become accurate and precise enough to be used in geobarometry (Enami et al. 2007; Kohn 2014).

Non-homogeneous pressure is documented for inclusion-host systems under stress due to difference in viscosity. In geological literature, this is known from analytical and numerical studies where pressure and stress distribution for different inclusion shapes, orientation and viscosity contrasts were investigated (Kenkmann and Dresen 1998; Tenczer et al. 2001; Schmid and Podladchikov 2003; Schmid 2005). Recently, Moulas et al. (2014) used 2D analytical solutions for the incompressible viscous flow problem in and around elliptical inclusions. They found that the viscosity contrast and aspect ratio of elliptical inclusions control the magnitude of the pressure difference inside and outside inclusions. In addition, the inclination of the inclusion with respect to the bulk compression direction controls the spatial distribution of pressure. They conclude that both weak and strong inclusions can develop large pressure variations depending on geometrical and rheological factors.

In multi-grain aggregates where grain shapes are generally more irregular than ellipses and viscosity may vary, the resulting stress and pressure distribution becomes complex (e.g., see Fig. 1 in Llana-Funez et al. 2012 and Fig. 4 in Tajčmanová et al. 2015). Studies of stress perturbations around inclusions involving also plastic deformation investigate the importance of non-homogeneous stress (and pressure) distribution on the formation of shear zones in polymineralic rocks (Misra and Mandal 2007). Whereas viscous stresses relax over time, elastic stresses will always be there as long as there is an applied load. Burnley (2013) calculated the stress patterns resulting from purely elastic deformation, including plastic yielding, and discussed the implications of these patterns for metamorphic banding. Schrank et al. (2012) investigate both experimentally and numerically the effects of thermal elasticity on stress distribution during heating of a granite. Other geological situations such as folding and fracturing bring along pressure variations as reviewed by Mancktelow (2008).

Non-homogeneous pressure in rocks due to viscosity contrasts, geometry and orientation has been shown to influence metamorphic reactions. Simpson and Wintsch (1989) describe myrmekite associated with K-feldspar "augen." Ruling out a magmatic origin of the myrmekite, they conclude that it formed during local stress differences on K-feldspar grain boundaries. Hwang et al. (2007) showed the interplay of crack formation due to stress concentrators around inclusions and the GRAIL reaction (garnet + rutile $=$ kyanite + ilmenite + qtz), known for its barometric purposes (e.g., Bohlen et al. 1983). These studies suggest that pressure variations have not dissipated during metamorphic reactions and therefore do not occur independently from reactions.

Schmid et al. (2009) investigated the reaction rate of enstatite rim growth in a coupled kinetic-mechanical model based on rim growth experiments (Milke et al. 2009). They showed that reaction rate was slowed down by the rheology of the matrix, manifested as different rim thickness grown around an inclusion. Furthermore, stress can have a direct effect on the phase equilibria. In particular, Robin (1974) documented that coherency of exsolution lamellae in feldspar causes elastic strains in the individual lamellae affecting the lattice parameters. For a very small proportion of pure coherent albite lamellae within an orthoclase grain, the values for stress correspond to $0.6 \mathrm{GPa}$ parallel to the b-axis and $2.3 \mathrm{GPa}$ orthogonal to the b-axis (Robin 1974). Values of 0.9 and $2.0 \mathrm{GPa}$ were obtained for a coherent albite precipitate in microcline (Pryer and Robin 1996). As a result, the position of the solvus in an equilibrium diagram is changed in case of coherency stress and is referred to as coherent solvus. If the pressure variations occur within a solid solution, such as plagioclase, chemical equilibrium will result in chemical zoning. Tajčmanová et al. (2014) developed an alternative geobarometer to infer pressure variations from chemical zoning by use of homogeneity of chemical potentials in which pressure was spatially varied.

The above-mentioned progress in research brings up several key questions. If there is a sufficient amount of arguments and models documenting the existence of pressure variations, why are isobaric models of metamorphic 
assemblages generally so successful? Are the pressure variations too small to have a significant effect on the main phase assemblages and textures? Or do we not recognize the evidence? For example, is the preservation of a prograde microstructure a result of sluggish kinetics or is it because some minerals are at a different pressure?

Here, we present a method based on Gibbs minimization that can be used to predict stable mineral assemblage and composition for systems in which pressure is not homogeneous. The main goal is to provide a method by which the above problems can be addressed in the future, rather than entirely solving them for specific observations. The presented method is a forward modeling technique to calculate equilibrium under spatial pressure variations that can be compared with observations. As current development in research shows that pressure variations can be maintained on the grain scale during metamorphism, the main motivation behind the development of an equilibrium method is to fit phase assemblages and chemical zoning as a result of pressure variation in space rather than in time. The method is first tested against results from a previously derived barometry method that was based on equal chemical potentials, followed by applications based on natural observations to explore the effect of heterogeneous pressure on phase equilibria and composition.

\section{Method}

Thermodynamic equilibrium under external forces (e.g., a fluid under gravity; Gibbs 1906; Landau and Lifshitz 1987) is characterized by gradients of thermodynamic state variables (e.g., pressure) while keeping zero macroscopic fluxes (Landau and Lifshitz 1987, p.236). An equilibrium formulation is used for several applications in chemical engineering and deep oil reservoirs for calculating compositional gradients under an external force such as gravity or an osmotic pressure difference across a semipermeable membrane (Gibbs 1906; Young et al. 1954; Miller 1956; Landau and Lifshitz 1987; Esposito et al. 2000; Wensink and Lekkerkerker 2004; Savenko and Dijkstra 2004; Martins et al. 2005; Mueller and Weiss 2012). For such applications, the chemical potential may be modified to account for the externally imposed force. Another chemical potential-based equilibrium approach was used by Tajčmanová et al. (2014) in a geologically relevant application to obtain pressure gradients from chemically zoned minerals in a binary system.

Alternatively, a constrained minimization approach can be used in which the conventional equal pressure formulation of Gibbs energy remains unmodified. Typically, the constraints in the minimization are the amounts of chemical components of the system. Koukkari and Pajarre (2011) demonstrate that the minimization procedure can include system or external potential variables with their conjugate coefficients as well as non-equilibrium affinities.

The method presented here extends the conventional Gibbs minimization approach for geological materials to systems with externally imposed pressure variations. The method is generalized for multi-component multi-phase systems formulated as a forward modeling technique. It provides a way of extending the chemical potential-based unconventional barometry method from single-phase binary to multi-component multi-phase systems.

\section{Gibbs energy calculation}

Gibbs energy of pure phases is calculated using the equations outlined in "Appendix 1" ("Pure phases" section) with the most recent version of the end-member dataset of Holland and Powell (1998) (with updated version in 2004). As we use a mass-based approach (see Tajčmanová et al. 2014, 2015), phase compositions and energy are converted to weight fraction and $\mathrm{J} / \mathrm{kg}$, respectively, by dividing over molecular mass of the phase. Solid solutions are generated as discrete phases systematically varying the composition following an approach similar to Connolly (2005). "Solid solutions" section of "Appendix 1" lists the utilized procedure to calculate of Gibbs energy of these solution phases. Worked examples in "Appendix 2" and the supplementary material demonstrate the site speciation calculation procedure for a selection of the programmed solution models.

\section{Constrained Gibbs energy minimization}

Constrained Gibbs energy minimization is performed using the LIPSOL linear optimization algorithm implemented in the function "linprog" in MATLAB (Zhang 1998b). The weight proportion of the $i$ th stable phase $\alpha_{i}$ is found such as to minimize system Gibbs energy:

$g_{\text {sys }}=\sum_{i=1}^{n} \alpha_{i} \cdot g_{i}$

Subject to the constraint:

$\sum_{i=1}^{n} \alpha_{i}=1$

and the constraint for the $j$ th system component:

$\sum_{i=1}^{n} x_{i}^{j} \cdot \alpha_{i}=x_{\mathrm{sys}}^{j}$

Multiple $P-T$ pseudo-sections have been calculated to ensure reproducibility of phase diagrams generated with 
the widely used and extensively tested thermodynamic software package Perple_X (Connolly 2005).

\section{Gibbs minimization with pressure constraints}

In case of pressure heterogeneity Gibbs minimization is subject to an additional set of constraints by analogy to mass balance above:

$\sum_{i=1}^{n} \alpha_{i}^{j}=\pi_{\mathrm{sys}}^{j}$

where $\pi_{\text {sys }}^{j}$ is the weight fraction of the system having pressure $P_{j}$ and $\alpha_{i}^{j}$ is the weight fraction of a $i$ th phase having pressure $P_{j}$. Equations 1, 2 and 3 have to be adjusted as follows:

$g_{\mathrm{sys}}=\sum_{j}^{m} \sum_{i=1}^{n} \alpha_{i}^{j} \cdot g_{i}\left(P^{j}, T\right)$

$\sum_{j}^{m} \sum_{i=1}^{n} \alpha_{i}^{j}=1$

$\sum_{j}^{m} \sum_{i=1}^{n} \alpha_{i}^{j} \cdot x_{i}^{k}=x_{\mathrm{sys}}$

where $k$ is the index for system component.

Input pressure constraints are assumed to satisfy:

$\sum_{j=1}^{m} \pi_{\mathrm{sys}}^{j}=1$

"Appendix 3" illustrates the generation of the equality constraint matrix using the above Eqs. 4-7. "Appendix 4" includes MATLAB scripts implementing Eqs. 1-3 for a standard calculation and a script for its generalization (Eqs. 4-7) to account for pressure variation. Examples of MATLAB scripts for the visualization of the results can be found in the supplementary material. In all example calculations documented in the result section below, the weight fraction of the system being at a specified pressure is set at $1 / m$, where $m$ is the number of pressure constraints. For a calculation in which only two different input pressures are defined, the weight fraction of the system having pressure $P_{j}$ is 0.5 , whereas ten input pressure constraints ensure each pressure $P_{j}$ to occupy one-tenth of the system.

It is possible to think of dividing the system in compartments each of which can have a distinct pressure. The stable phase assemblage and composition are then found for which the Gibbs energy of the entire system is lowest while conserving total mass of the system.

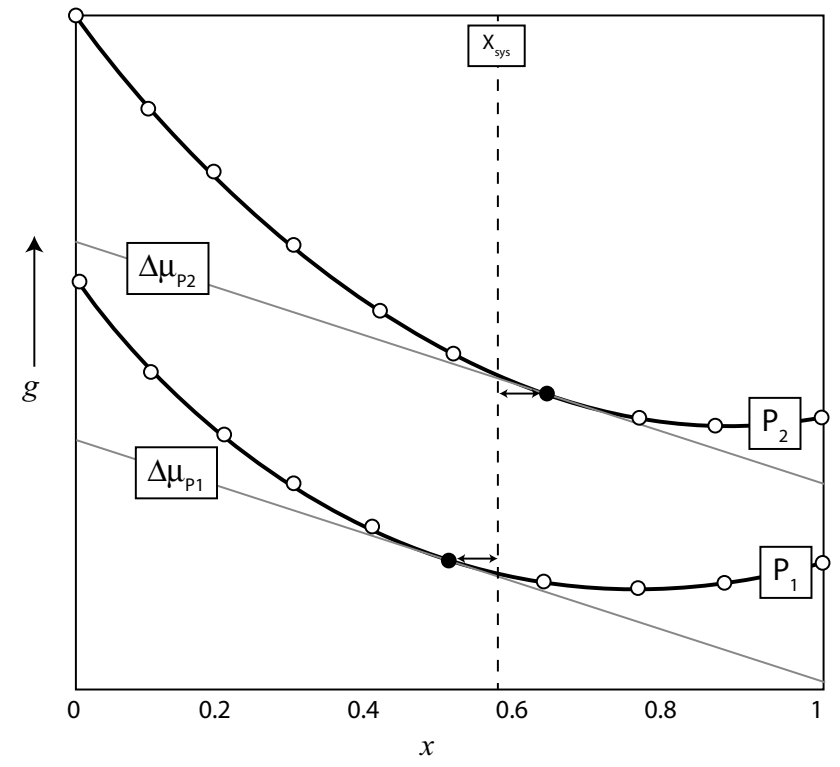

Fig. 1 Diagram showing the concept of constrained Gibbs minimization for a closed binary system under a pressure gradient. Two curves (thick solid lines) display the partial Gibbs energy $(g)$ of the solid solution, each at different pressure $\left(P_{1}\right.$ and $\left.P_{2}\right)$. Open circles on the curve symbolize the discretized phases of the solutions that are input into the minimizer. For a system composition fixed at $X_{\text {sys }}$ (dashed straight line), the minimum Gibbs energy of the system is given by a mixture of two of the discretized phases each lying on a different Gibbs energy curve to fulfill the pressure constraint. With the weight fraction of the system at each pressure constrained at $1 / n P$, half will be at the $P_{1}$ curve and the other half at $P_{2}$. Horizontal arrows indicate the deviation of the stable phase composition from $X_{\text {sys. }}$. Two straight lines (thin solid lines) show the difference in chemical potentials of the two end-members for each pressure $\left(\Delta \mu_{P 1}\right.$ and $\left.\Delta \mu_{P 2}\right)$. From theoretical predictions, these two lines are parallel in equilibrium (as in that case gradients in chemical potential difference have vanished and there are no macroscopic fluxes in the system). As can be seen from the diagram, this is equivalent to the result of the Gibbs energy minimization

Figure 1 illustrates a conceptual example in a $\mathrm{G}-\mathrm{X}$ diagram for a binary solution phase in which two different pressures exist. The compositions of the phase are discretized (white circles in Fig. 1) for both pressures $\left(P_{1}\right.$ and $\left.P_{2}\right)$. System composition is constrained at $X_{\text {sys }}$, and fraction of the system at $P_{1}$ is set to 0.5. Consequently, the global minimum of energy is reached with a phase assemblage that consists of two (discretized) phases each at a different pressure such that $X_{\text {sys }}$ is satisfied (black circles in Fig. 1). The slope of the $\mathrm{g}-\mathrm{x}$ curves being equivalent to the driving force for diffusion $(\Delta \mu$, see review in Tajčmanová et al. 2015) is equal for both points $\left(\Delta \mu_{P 1}-\Delta \mu_{P 2}=0\right)$. Hence, the system is in thermodynamic equilibrium, and the global minimization approach is equivalent to the chemical potential-based approach. 


\section{Applications and results}

The method is applied to two binary single-phase geological examples (plagioclase and orthopyroxene). For these two examples, the input pressure is obtained from the unconventional barometry method using chemical potentials. Therefore, it also provides a benchmark of the two methods. Then, these two examples are extended to a binary multi-phase system. The effect of systematically varying the input pressure gradient on stable phase assemblage in a multi-phase, multi-component system is explored in a third geological example followed by two examples for a specific micro-texture in a complex multi-phase system. Finally, equilibrium is calculated for a multi-phase, multicomponent system using pressure obtained from a $2 \mathrm{D}$ mechanical model inspired by natural observations.

\section{Plagioclase rims}

Plagioclase formed as rims around kyanite during decompression in rocks from the Bohemian massif and is described in detail in earlier work (Tajčmanová et al. 2011). The anorthite component in plagioclase $\left(X_{\text {an }}\right)$ decreases from the kyanite toward the matrix. This zoning can be interpreted as being in thermodynamic equilibrium with a mechanically feasible model in which pressure decreases from the kyanite toward the matrix (Tajčmanová et al. 2014). The presented minimization method is used to predict the compositional zoning from the derived pressure gradient. First, a $P-T$ pseudo-section is generated with the Gibbs energy calculated according to "Appendix 1" and the minimization as outlined above. Figure 2 shows the phase diagram for a plagioclase consisting of $50 \%$ anorthite and $50 \%$ albite (see Table 1 for bulk compositions in all figures). The calculated phase assemblages, proportions and compositions are benchmarked to calculations with Perple_X 6.6.8 (see Suppl. Fig. 1) to rule out errors in the Gibbs energy of phases and the minimization algorithm. Then, for a temperature fixed at $800{ }^{\circ} \mathrm{C}$, the system composition is set to the average composition of the plagioclase rim, and the pressure gradient derived from the zoning is added to a matrix pressure of $1.0 \mathrm{GPa}$ to use as additional constraints. All possible phases for this composition are considered in the calculation to avoid prescribing the stability of feldspar as a result. Figure 3 shows that the two different employed solution models predict the observed zoning within error of measurement. The fit is better for the solution model of Holland and Powell (2003) as the pressure gradient was derived using this model (Tajčmanová et al. 2014). With the matrix pressure set to $1.0 \mathrm{GPa}$ as estimated by Tajcmanová et al. (2011), the stable phase assemblage consists of just plagioclase. When the matrix pressure is set at $2.0 \mathrm{GPa}$, kyanite, jadeite, quartz and grossular are

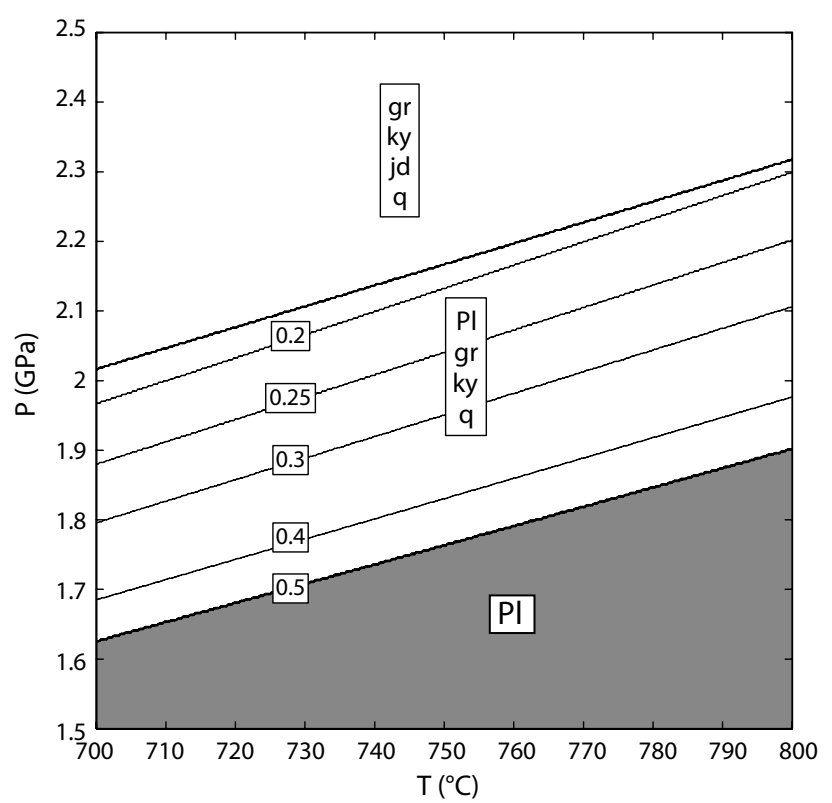

Fig. 2 P-T diagram in NCAS for a plagioclase (50\% An) bulk composition. Isopleths of mole fraction An in plagioclase are indicated with rectangular labels. The $P-T$ range over which the GASP reaction takes place is enclosed by thick solid lines. Variance is indicated with gray shading conform pseudo-section diagrams in Perple_X. The resultant diagram here produced with our MATLAB formulation of Perple_X (see "Appendix 1") is identical to the one created with Perple_X 6_6_8 (see Suppl. Fig. 1). The diagram shows that anorthite content decreases with pressure, which remains true for the more complex composition of the sample from the Bohemian Massif (e.g., Tajčmanová et al. 2011)

predicted on the high-pressure side within the rim which is not observed. Hence, the Gibbs minimization method constrains also the absolute pressure in addition to benchmarking the two methods for the compositional zoning under pressure variations in plagioclase.

\section{Orthopyroxene zoning}

Primary orthopyroxene (Opx) from the diamond-grade ultra-high-pressure (UHP) spinel-garnet peridotite body at Svartberget in the Western Gneiss Region (WGR), Norway, was metamorphosed during the Caledonian Orogeny. It occurs in an assemblage with spinel, olivine, clinopyroxene, garnet and $\mathrm{Fe}-\mathrm{Ti}$ oxides (mainly magnetite, ilmenite). The locality and rocks containing the Opx are described in detail by Vrijmoed et al. (2006; 2013). The Opx shows typically bowl-shaped zoning of $\mathrm{Al}_{2} \mathrm{O}_{3}$, where $\mathrm{Al}_{2} \mathrm{O}_{3}$ content increases from core to rim. In equilibrium with garnet, the $\mathrm{Al}_{2} \mathrm{O}_{3}$ content in Opx is pressure dependent and used as geobarometer in Opx-eclogites and garnet-peridotites (Macgregor 1974; Brey and Köhler 1990; Carswell and Harley 1990; Ravna-Krogh and Paquin 2003; Nimis and Grutter 2010). Assuming the core of the Opx was in 


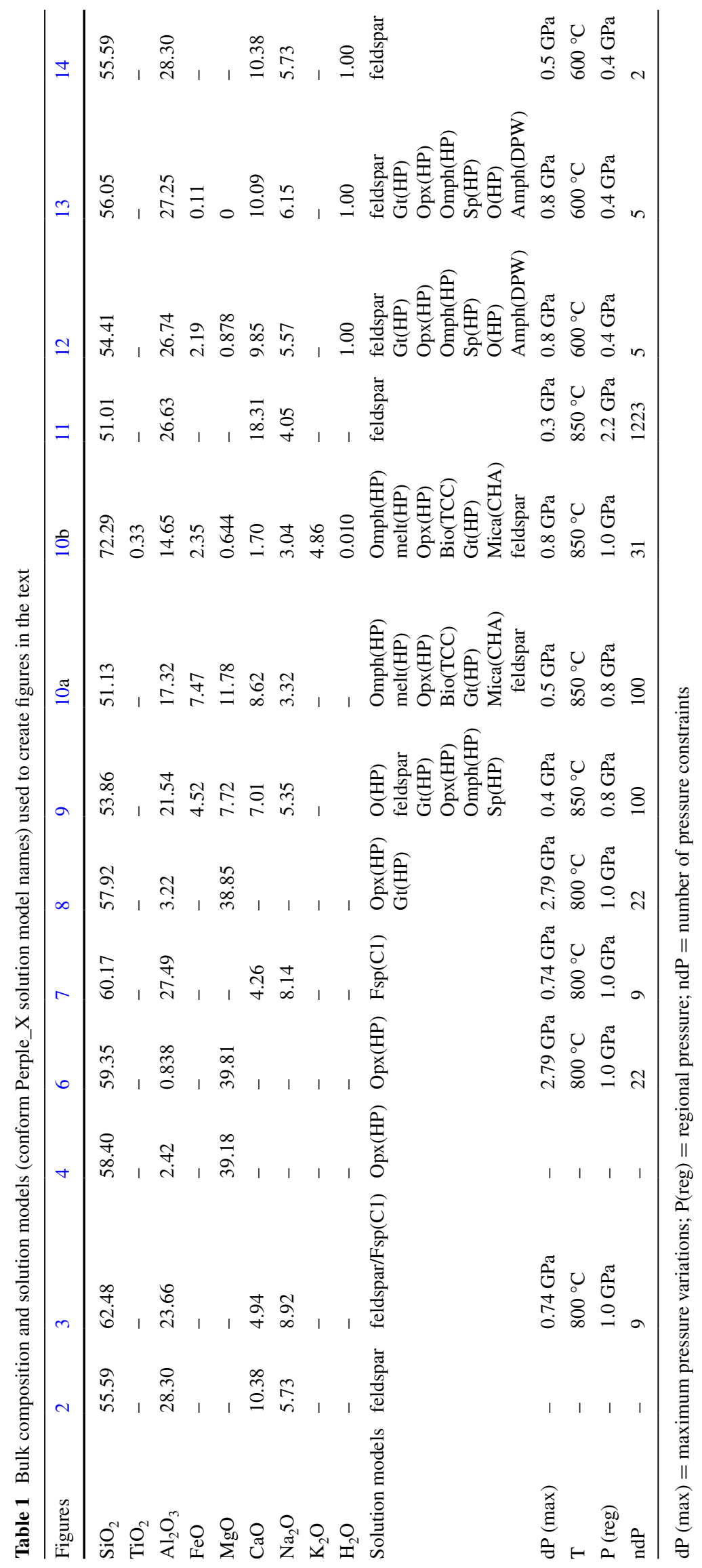


Fig. 3 Results of constrained Gibbs minimization for average composition $\left(0.26 X_{\text {an }}\right)$ of plagioclase rim under the pressure gradient. The blue and green curves are the predicted phase compositions using, respectively, the Holland and Powell (2003) ternary feldspar model ("Fsp(C1)" in Perple_X) and the Fuhrman and Lindsley (1988) model ("feldspar" in Perple_X). Red circles indicate the measured compositions. The bottom figure shows the input pressure gradient as derived by Tajčmanová et al. (2014)
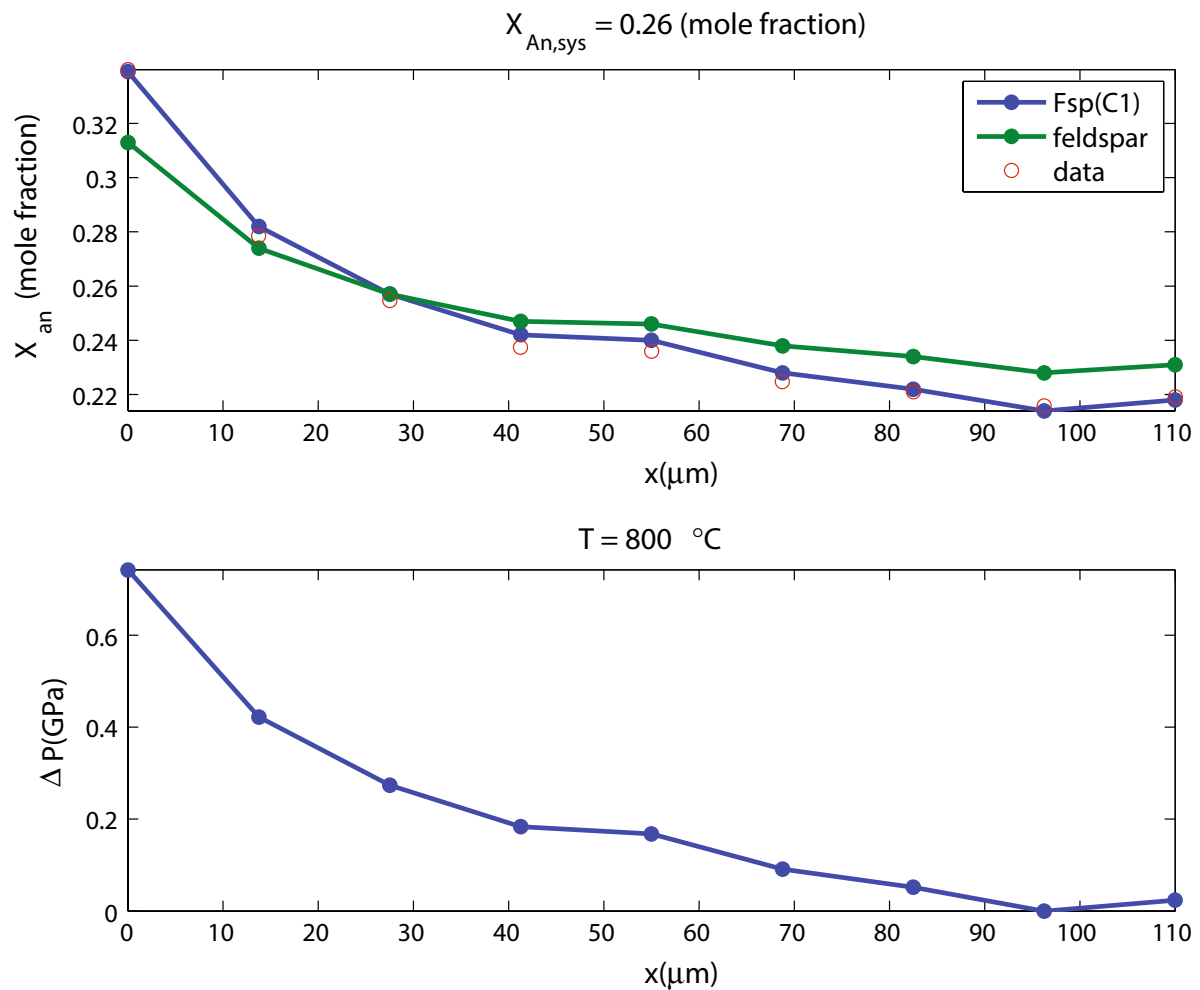

equilibrium with garnet at peak conditions, the pressure can be estimated and the zoning interpreted as retrograde diffusion effect. Recent investigations show the Opx zoning is more complex and does not fit diffusional profiles but is possibly linked to metasomatic processes (Fig. 11d in Vrijmoed et al. 2013). Diffusion of $\mathrm{Al}$ in Opx is usually assumed slow, mostly based on $\mathrm{Al}$ diffusion experiments in Cpx (Smith and Barron 1991; McFarlane et al. 2003). Wood (1974) experimentally calibrated Al diffusion in Opx in equilibrium with garnet resulting in orders of magnitude faster diffusion coefficients. Additionally, the UHP domains in the WGR remained at high temperature for 14-20 Ma (Krogh et al. 2011). Thus, the question whether diffusion was sufficiently fast to homogenize $\mathrm{Al}_{2} \mathrm{O}_{3}$ in $\mathrm{Opx}$ at the Svartberget locality is still open. If $\mathrm{Al}$ diffusion in Opx was indeed too slow, the zoning may be preserved as disequilibrium features produced during metasomatism. Alternatively, the possibility that the zoning is a result of equilibrium under pressure variations can be investigated.

The two equilibrium methods (chemical potential and Gibbs minimization) are used to investigate how Al zoning in these Opx crystals is distributed at equilibrium under a pressure gradient. Using both approaches allows to benchmark the two methods on a different chemical system in a different mineral. The dominant pressure dependence of $\mathrm{Al}$ in Opx is captured by the reaction between enstatite, $\mathrm{Mg}$ Tschermak's molecule and pyrope (e.g., Wood 1974). For simplicity, the Opx solution is treated as binary between the $\mathrm{Mg}$ end-member (enstatite) and the $\mathrm{Al}$ end-member (Mg-Tschermak's). The Opx solution model of Holland and Powell (1996) is used. Figure 4 shows a P-T section for a system consisting of enstatite, diluted with 5 mol percent pyrope (benchmarked with Perple_X calculation in Suppl. Fig. 2). Isopleths of $\mathrm{Al}_{2} \mathrm{O}_{3}$ weight percent in $\mathrm{Opx}$ show the essential behavior of the Al-in-Opx geobarometer. Figure 5 shows a possible pressure gradient $(P$ needed to homogenize $\Delta \mu$ ) for the zoning in Opx 8-4 (Fig. 4b in Vrijmoed et al. 2006). As the chemical potential method delivers only the pressure gradient, an absolute value of pressure at a point in the profile is chosen. With a value of 2.6 GPa at the rim on the left side, the pressure decreases toward the core to around $0.15 \mathrm{GPa}$. The resultant pressure gradient is used as pressure constraints for the Gibbs minimization method in addition to the average composition of Opx as system composition. From all possible phases in the HP dataset, only Opx is stable at the input pressures and system composition. A higher pressure at the rim will predict garnet in addition to Opx, which therefore constrains the absolute pressure along the profile. Figure 6 shows how the measured $\mathrm{Al}_{2} \mathrm{O}_{3}$ content is reproduced with the pressure profile obtained using the chemical potential approach, thereby again confirming the reliability of both methods. Similar to the case of plagioclase, the zoning is opposite to what is expected from a conventional $P-T$ diagram (Fig. 4) where $\mathrm{Al}_{2} \mathrm{O}_{3}$ content decreases with increasing pressure. It is consistent with the Mg-Tschermak's 


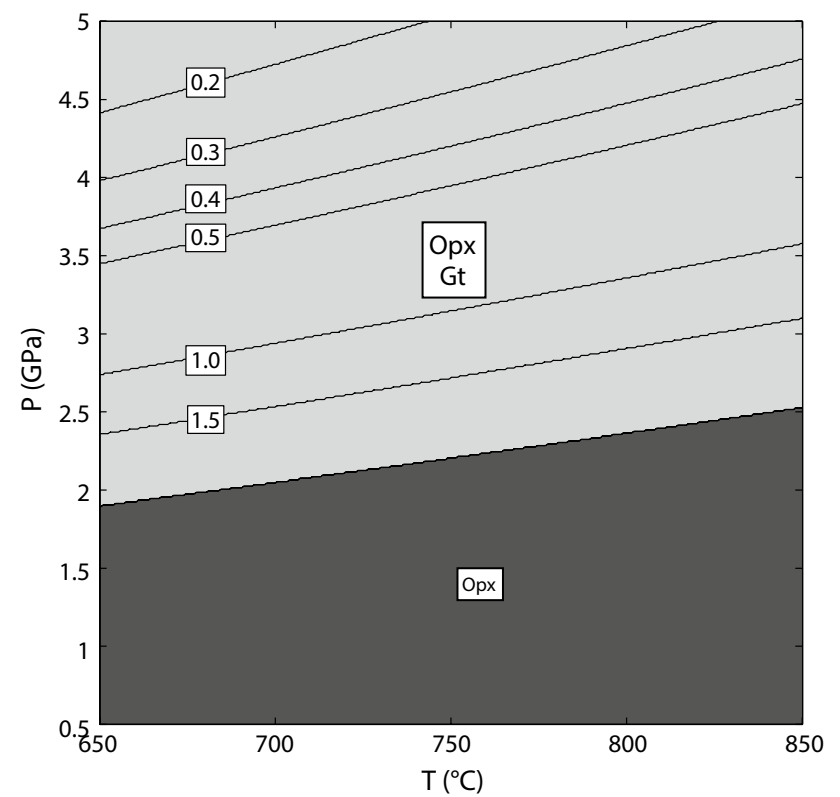

Fig. $4 P-T$ diagram in MAS for enstatite with $0.1 \%$ Mg-Tschermak's (MgTs). Isopleths of $\mathrm{Al}_{2} \mathrm{O}_{3}$ (wt $\%$ ) are labeled with rectangular boxes. $\mathrm{Al}_{2} \mathrm{O}_{3}$ content of Opx in equilibrium with garnet (pyrope) decreases with pressure which forms the basis of the Opx-garnet geobarometry. Variance is indicated with gray shading conform pseudosection diagrams in Perple_X. Identical results are obtained with Perple_X (see Suppl. Fig 2) end-member having a higher density than the enstatite end-member.

\section{Multi-phase predictions}

The formulation shown above treats also multi-phase systems. The single-phase example above already included all possible phases in the dataset in the minimization. Therefore, only system composition needs modification. As an example, the calculations were repeated for the two cases treated above. For the plagioclase rim, the system composition was modified to include part of the kyanite inclusion. The result is shown in Fig. 7 and demonstrates the ability of the method to also predict the observed kyanite on the high-pressure side of the inclusion. Hence, this phase assemblage can be in equilibrium under the given input pressure gradient. For the Opx example, a small amount of garnet (pyrope) was mixed with the average composition of the Opx to define the system composition input (see Table 1). The result in Fig. 8 shows that garnet is stable at highest pressures at the rims of the Opx, consistent with observations of garnet adjacent to Opx. It is noted here that the conventional Al-in-Opx barometry still applies at the contact between garnet and Opx. This means that higher pressure at the garnet-Opx interface will decrease $\mathrm{Al}_{2} \mathrm{O}_{3}$ concentration in Opx at the rim.
Fig. 5 Results of unconventional barometry for Opx in Svartberget peridotite at $800^{\circ} \mathrm{C}$. a. Contour diagram of $\Delta \mu$ $\left(\mu_{\mathrm{en}}-\mu_{\mathrm{mgts}}\right)$ for variable pressure and measured composition along the profile (distance between analyses $\sim 35 \mu \mathrm{m}$ ). The equilibrium state follows contours (i.e., where $\Delta \mu$ is constant). White line shows the pressure profile for a rim pressure set to $\sim 2.6 \mathrm{GPa}$. b Measured $\mathrm{Al}_{2} \mathrm{O}_{3}$ wt $\%$ across the Opx grain. c Pressure profile corresponding to the chosen isopleth of $\Delta \mu$ from figure a. d Calculated density $\left(\mathrm{kg} / \mathrm{m}^{3}\right)$ across the Opx grain corresponding to the pressure profile of $\mathbf{a}, \mathbf{b}$. Density increases with pressure as the concentration of the densest end-member (MgTs) increases
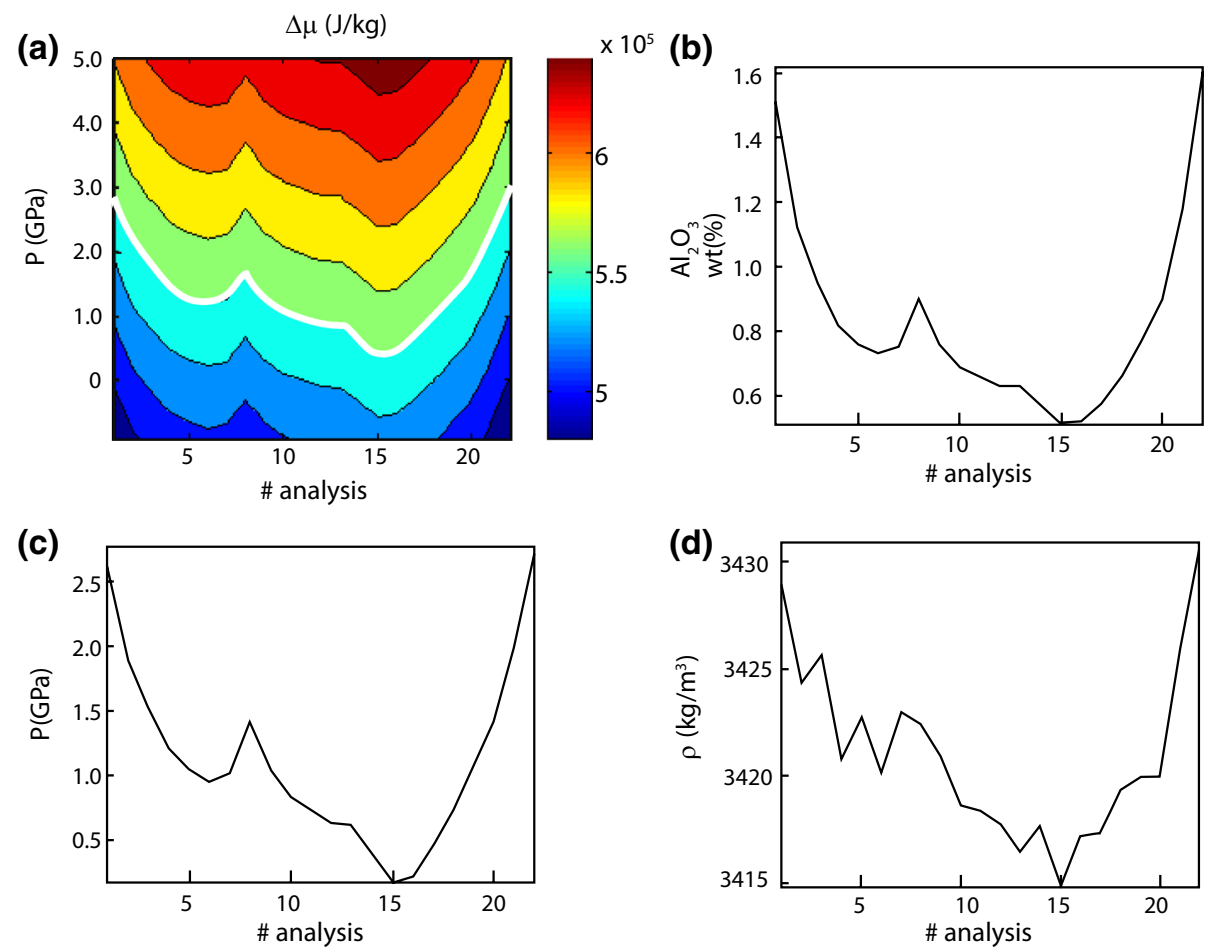
Fig. 6 Results of constrained Gibbs minimization for average composition of Opx grain 8-4a (from Vrijmoed et al. 2006) under the pressure gradient obtained from Fig. 5. a The blue solid line shows predicted $\mathrm{Al}_{2} \mathrm{O}_{3}$ wt $\%$ content in Opx using the Gibbs minimization approach. System composition was constrained at average $\mathrm{Al}_{2} \mathrm{O}_{3}$ $\mathrm{wt} \%$ in the grain. Red circles are compositions measured with microprobe and are predicted by the model within error of measurement. b Pressure profile used as constraints in the Gibbs minimization. Solution model based on Holland and Powell (1996) (equivalent to Opx(HP) in Perple_X)
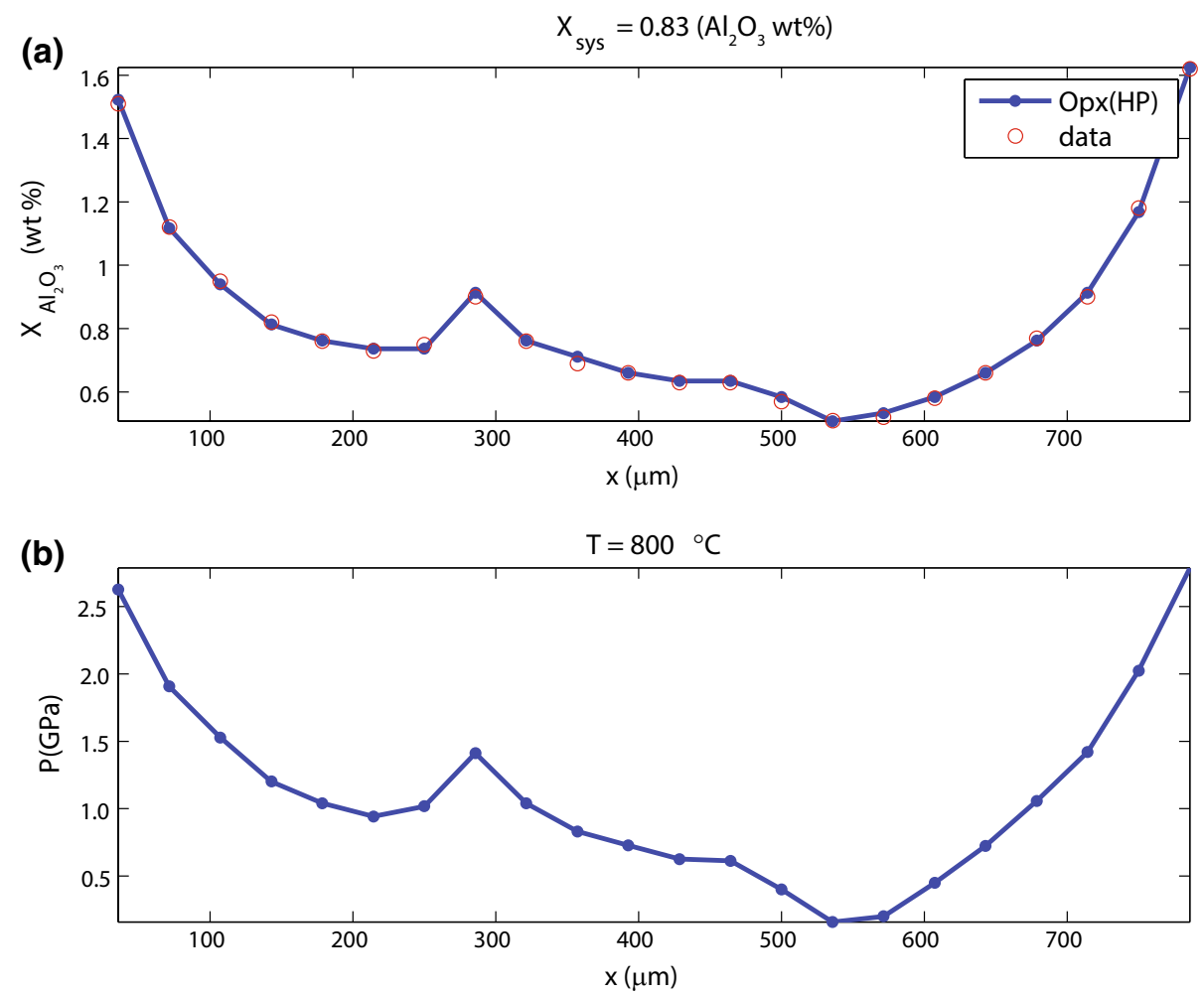
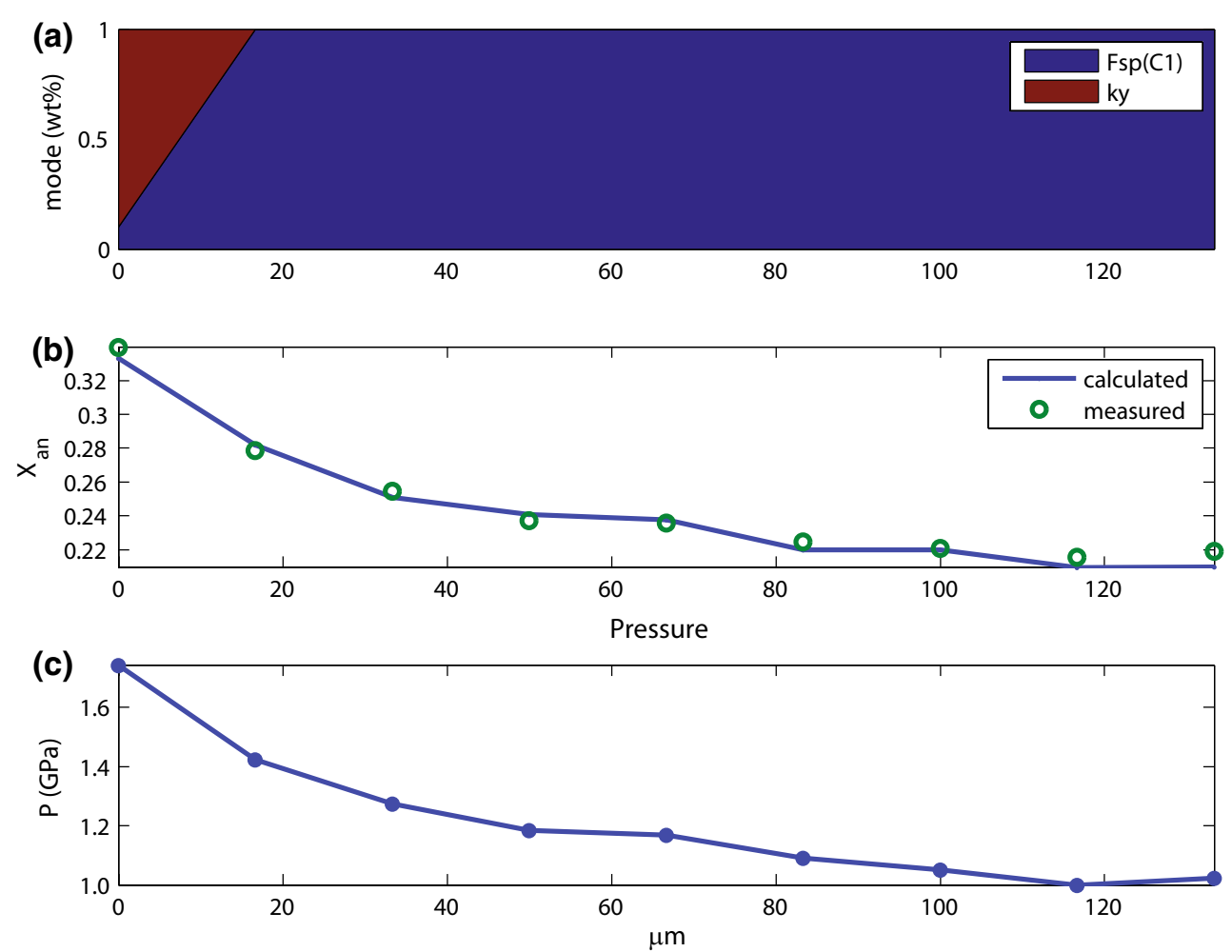

Fig. 7 Results of constrained Gibbs minimization for compositional mixture of plagioclase rim in Fig. 3 and adjacent kyanite. The same pressure gradient as in Fig. 3 was input as constraints. a Modal percentage of stable phases as cumulative plot. The model predicts nearly $100 \%$ kyanite stable at the high-pressure side (adjacent to the highest $X_{\mathrm{An}}$ of the plagioclase rim), as observed in the rock. b Predicted $X_{\text {an }}$ in the plagioclase rim similar to the prediction in Fig. 3. c Input pressure gradient (note: this is absolute $P$ not $\Delta P$ ) 

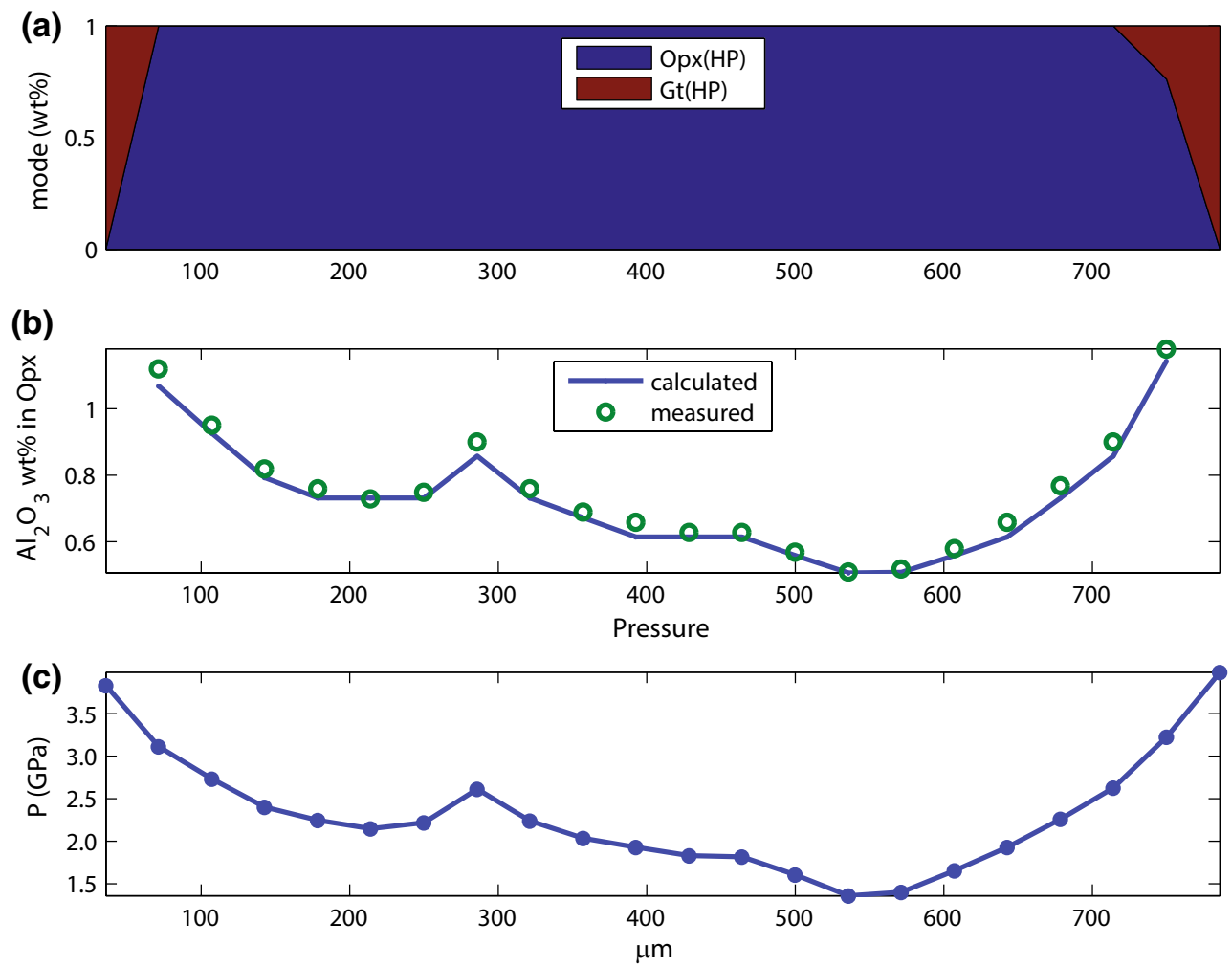

Fig. 8 Results of constrained Gibbs minimization for mixture of Opx grain in Fig. 6 and surrounding garnet. The same pressure gradient as Fig. 6 was input as constraints. a Modal percentage of stable phases.

\section{Sensitivity of phase assemblage to pressure gradient}

To show the sensitivity of phase assemblage on pressure gradient, a series of calculations was done for a relatively simple multi-phase, multi-component system consisting of olivine-plagioclase, an assemblage that is, for example, encountered in anorthosites of the Jotun nappe (e.g., Griffin 1971). Stable phase assemblage but also spatial distribution of the phases strongly depends on the pressure gradient (Fig. 9). The input composition consisted of $20 \mathrm{wt} \%$ olivine of composition given in Table 1 of Griffin (1971) and $80 \mathrm{wt} \%$ plagioclase $\left(\mathrm{An}_{42}\right.$ from Table 1 in Griffin 1971). Pressure decays gradually from the left toward a constant pressure value on the right (Fig. 10). As a first observation, it is noted that in a corona-type structure there is clear separation of mineral zones as a result of varying pressure in space, while the entire system is in thermodynamic equilibrium (as opposed to corona structures being the result of disequilibrium). On the right, plagioclase is stable separated from garnet (and minor amount of spinel) by a corona of olivine and clinopyroxene. Changing the pressure distribution to a more gently decaying profile results in thickening of some of the rims and thinning of others, occasionally changing mineralogy (i.e., Opx appearance in second
Garnet is predicted at both high-pressure sides of the Opx. b Predicted $\mathrm{Al}_{2} \mathrm{O}_{3}$ weight percent in the Opx grain similar to the prediction in Fig. 6. $\mathrm{c}$ Input pressure

profile). The maximum pressure variation is only $0.4 \mathrm{GPa}$, implying that small changes in pressure gradient can have noticeable effect on mineral modes.

\section{Complex multi-phase systems}

The example above was motivated by observations on corona structures described by Griffin (1971). Although distinct mineralogical zones are observed, the simple Gaussian pressure distribution does not lead to the observed sequence of mineralogical zones in the corona structures. The most common coronas have a core of orthopyroxene surrounded by successive shells of clinopyroxene and garnet. Some of the more complex coronas have a core of olivine within the orthopyroxene (Griffin 1971). We show in Fig. 10a that it is possible to match the observations more closely with a more complex pressure gradient and multimineral mixture. The system composition consisted of a mixture composed of $5 \%$ olivine, $20 \%$ orthopyroxene, $10 \%$ clinopyroxene I, $10 \%$ clinopyroxene II, $10 \%$ garnet I, $2 \%$ spinel II and the remaining $43 \%$ plagioclase using the observed mineral compositions from Table 1 in Griffin (1971). With a pressure gradient composed of pressure jumps and gradients, it is possible to obtain the observed 
Fig. 9 Cumulative phase mode diagrams along a $1 \mathrm{D}$ section showing the effect of varying pressure gradients on phase assemblage in multi-component, multi-phase system (NCFMAS) consisting of $20 \%$ olivine and $80 \%$ plagioclase. Pressure (GPa) input gradient (black dotted line; scale on right axis) is computed as $8+4 \cdot e^{-x^{2}} / \lambda$ where $\lambda$ is varied as indicated on each profile. Solution models used in the calculation with the corresponding name of the solution model in Perple_X (see solution_model.dat available for download from http://www. perplex.ethz.ch/); clinopyroxene: Omph(HP); ternary feldspar: feldspar; garnet: Gt(HP); spinel: $\mathrm{Sp}(\mathrm{HP})$; olivine: $\mathrm{O}(\mathrm{HP})$; orthopyroxene: $\mathrm{Opx}(\mathrm{HP})$. See Table 2
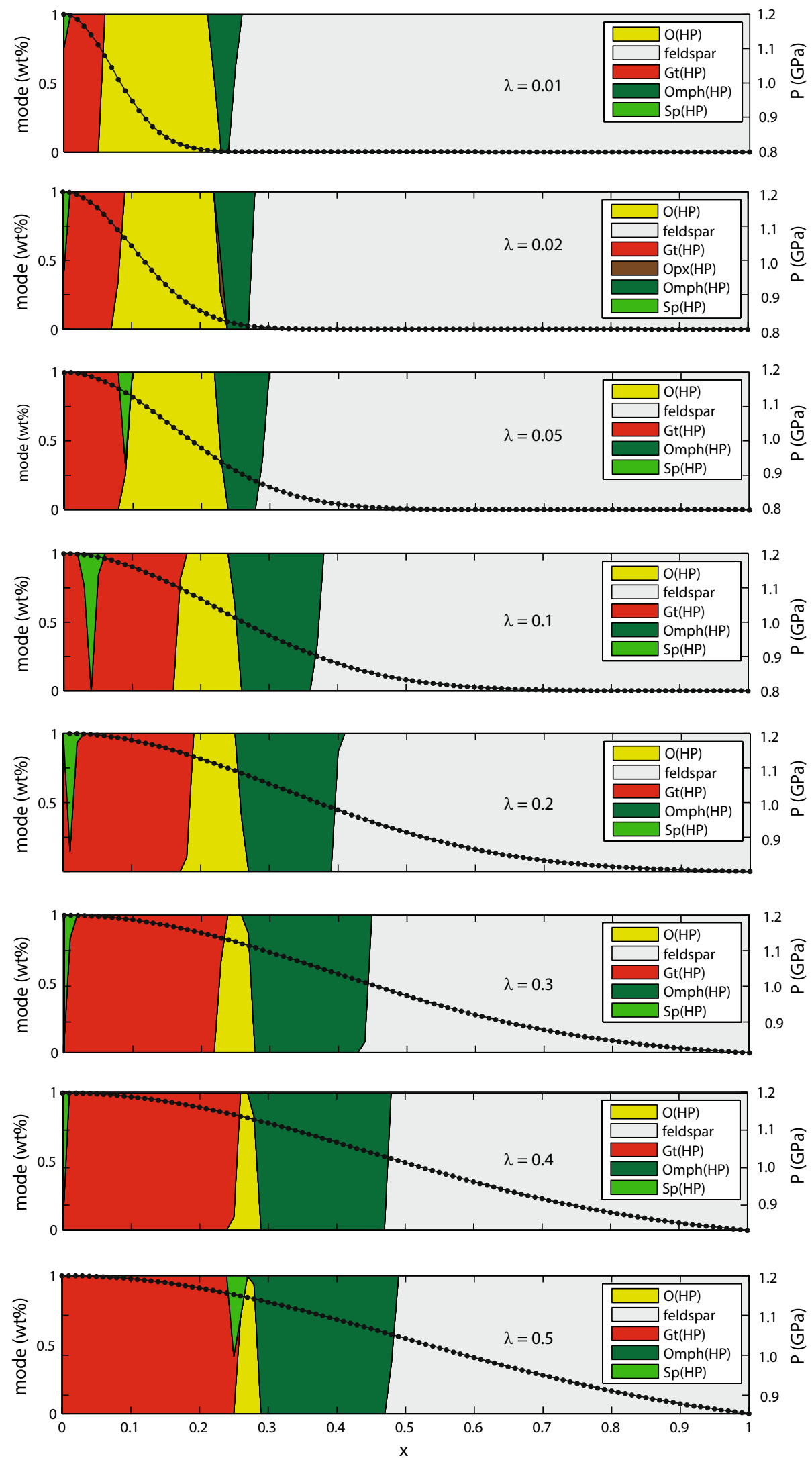

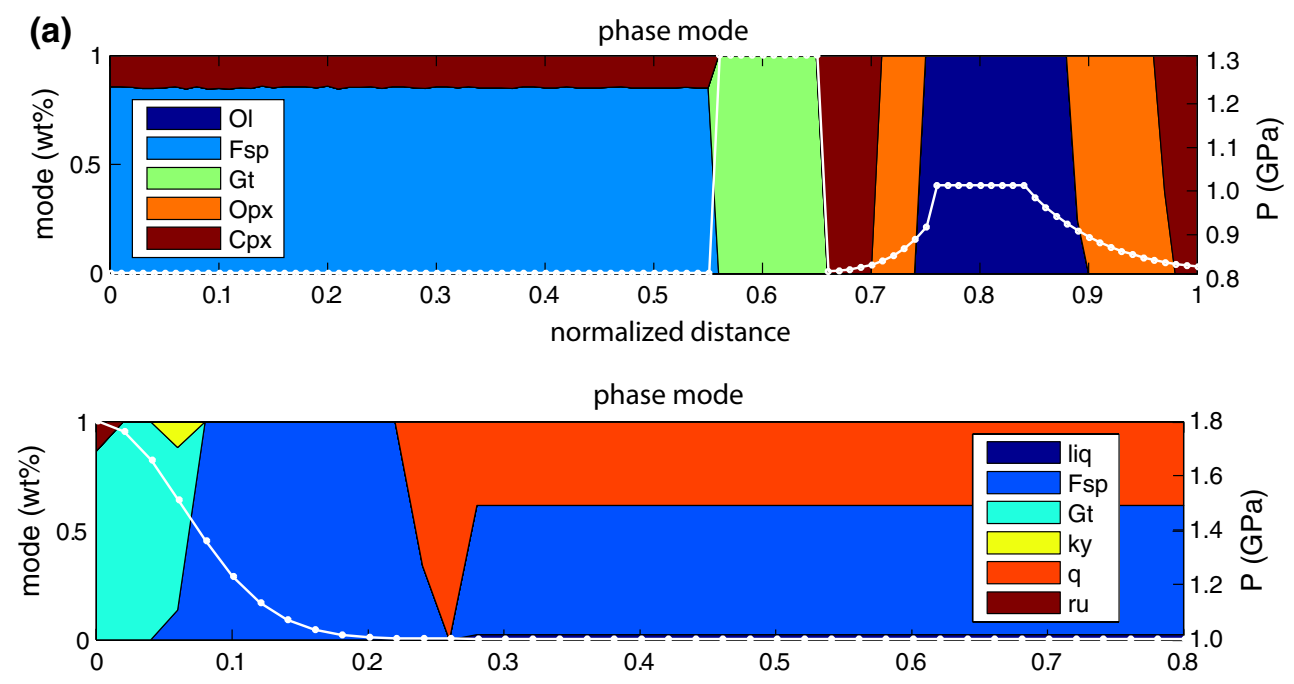

(b)

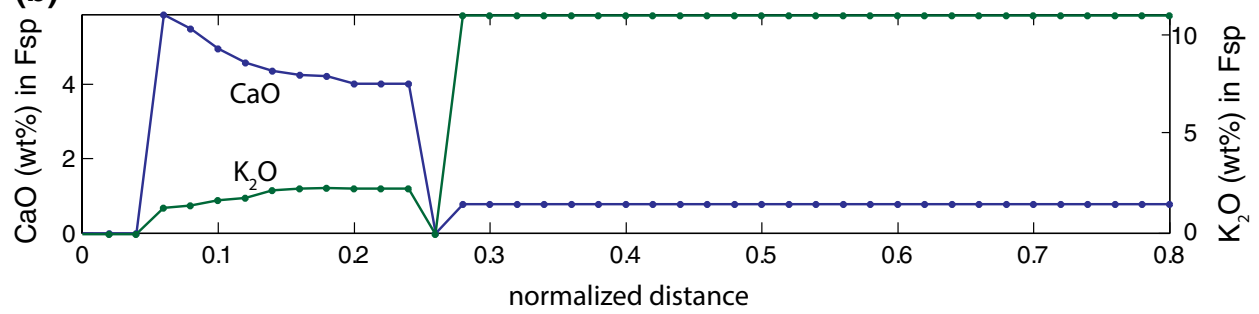

Fig. 10 a Results of constrained Gibbs minimization for bulk rock composition consisting of a mixture of minerals from Griffin (1971). The stable phase assemblage is shown in a cumulative plot of the phase modes (wt\%). White dotted line shows input pressure gradient (axis on the right). Note that varying thickness of Opx zones around olivine can be due to asymmetry in the pressure profile, while purely diffusion-controlled growth should result in equal thickness of zones. b Results of constrained Gibbs minimization for bulk rock composition in NCKFMASHT (from Fig. 5 in Tajčmanová et al. 2011). Upper panel shows a cumulative plot of the phase modes (wt\%). White dotted line shows input pressure gradient (axis on the

sequence of the more complex coronas. In addition, asymmetry in the profile leads to asymmetry in thickness of the mineralogical zones in the coronas which is often observed but hard to explain with purely diffusion-controlled corona growth. Note that these calculations only show the potential of exploring the possibility that such corona structures may be explained with a pressure gradient at chemical equilibrium, rather than solving a fully inverse coupled thermomechanical-reactive model.

For a more complex multi-component, multi-phase system, the case of plagioclase rims around kyanite is extended to include the matrix in which the texture occurs. Computations were done in the system $\mathrm{SiO}_{2}, \mathrm{TiO}_{2} \mathrm{Al}_{2} \mathrm{O}_{3}$, $\mathrm{MgO}, \mathrm{FeO}, \mathrm{CaO}, \mathrm{Na}_{2} \mathrm{O}, \mathrm{K}_{2} \mathrm{O} \mathrm{H}_{2} \mathrm{O}$ for the same bulk rock composition and solution models as in Tajčmanová et al. (2011). A benchmark for equal pressure and temperature with Perple_X is provided in the Suppl. Material. Over part right). Lower panel shows composition of feldspar in terms of anorthite (left axis; blue curve) and orthoclase component (right axis; green curve). Garnet, kyanite and rutile are predicted on the highpressure side, separated by a rim of zoned plagioclase from quartz, $\mathrm{K}$-feldspar ( \pm melt). Solution models used in the calculation with the corresponding name of the solution model in Perple_X (see Table 2) are biotite: $\mathrm{Bio}(\mathrm{TCC})$; clinopyroxene: $\mathrm{Omph}(\mathrm{HP})$; ternary feldspar: feldspar; garnet: $\mathrm{Gt}(\mathrm{HP})$; white mica: $\mathrm{Mica}(\mathrm{CHA})$; orthopyroxene: Opx(HP); melt: melt(HP). Abbreviations: liq melt, Fsp feldspar, $G t$ garnet, $O l$ olivine, $O p x$ orthopyroxene, $C p x$ clinopyroxene, $k y$ kyanite, $q$ quartz; $r u$ rutile

of the 1D section the pressure gradient similar to the one derived by Tajčmanová et al. (2014) is used as input for the constrained Gibbs minimization (Fig. 10b). The remaining part of the cross section is set to the matrix pressure (1.0 GPa). On the high-pressure side, the predicted phases are garnet, kyanite and rutile separated by a zoned plagioclase rim from a low-pressure assemblage consisting of quartz, K-feldspar and melt. The zone of plagioclase that separates the low- and high-pressure phases is chemically zoned from high to low anorthite content going toward low pressure as obtained above for single plagioclase rim, consistent with results from Tajčmanová et al. (2014). In addition to kyanite being stable at the high-pressure side as obtained for the multi-phase example above, there is also garnet, which is due to the $\mathrm{FeO}$ and $\mathrm{MgO}$ content of the bulk rock composition. Thus, garnet is expected to be stable at local high-pressure domains in the rocks, just as 


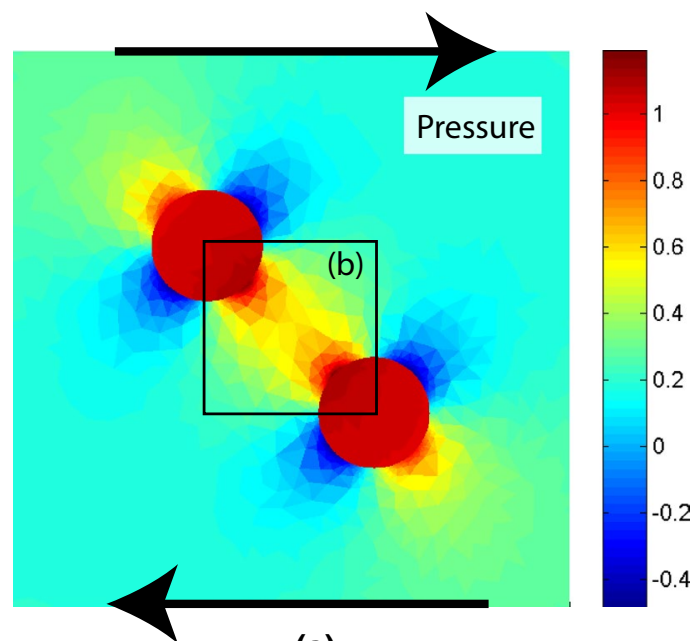

(a)

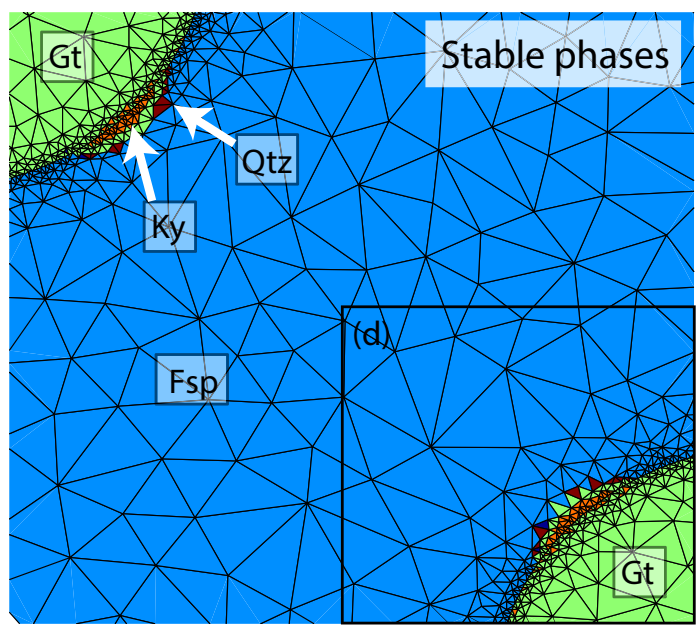

(c)

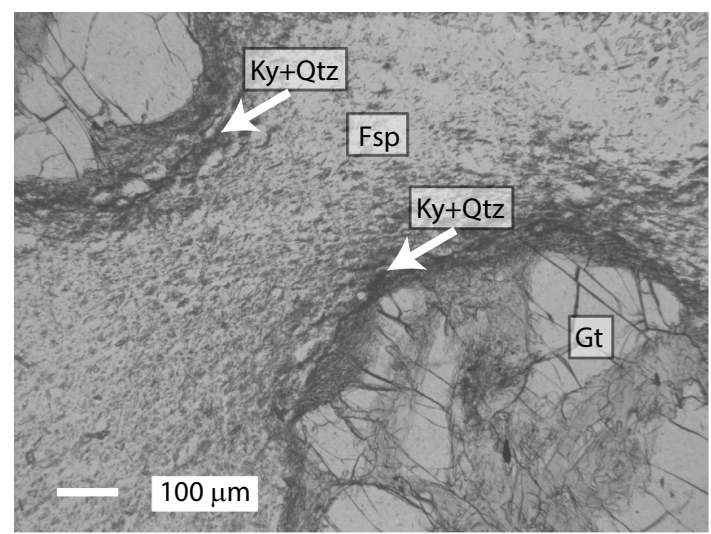

(e)

Fig. 11 Results of Gibbs minimization under constrained pressure in a $2 \mathrm{D}$ domain. a Dimensionless pressure variations (local mean stress) calculated with a FEM model for two high-pressure inclusions in a shear zone (shear sense indicated with black arrows) (model boundaries are further outside the figure). Rectangle shows zoom in $\mathbf{b}$. b Pressure map used as constraints in the minimization. The pressure was obtained by normalizing to the maximum pressure in the domain

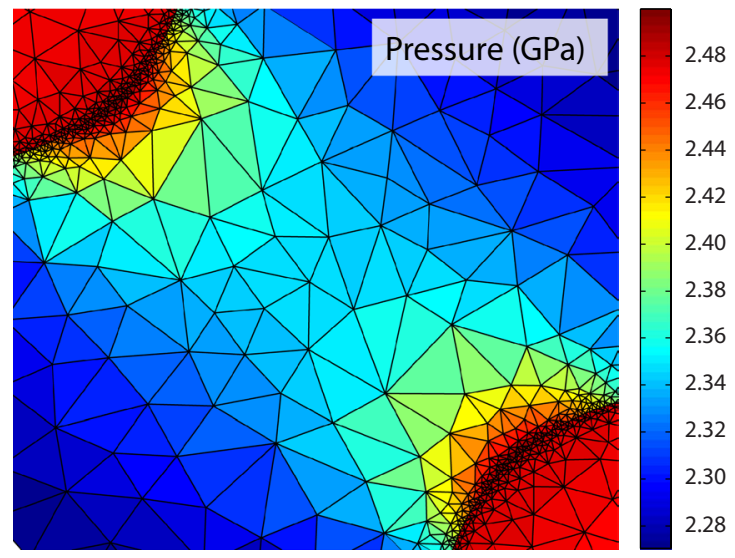

(b)

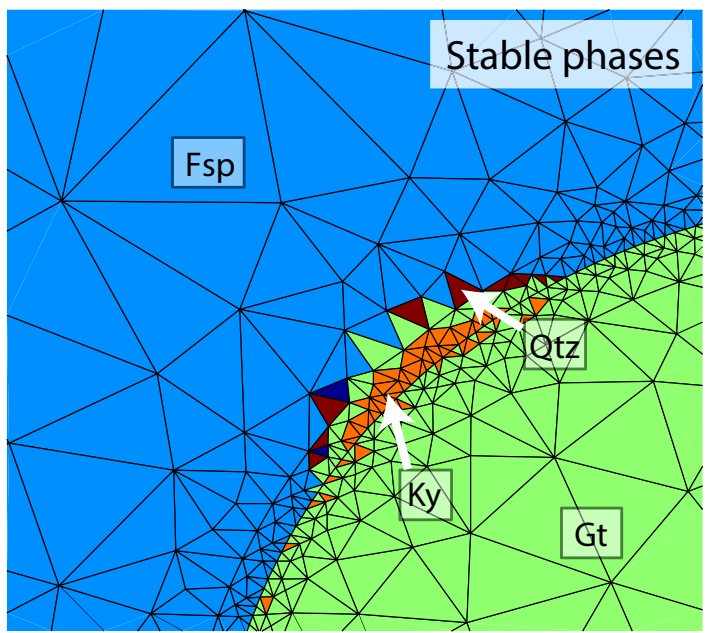

(d)

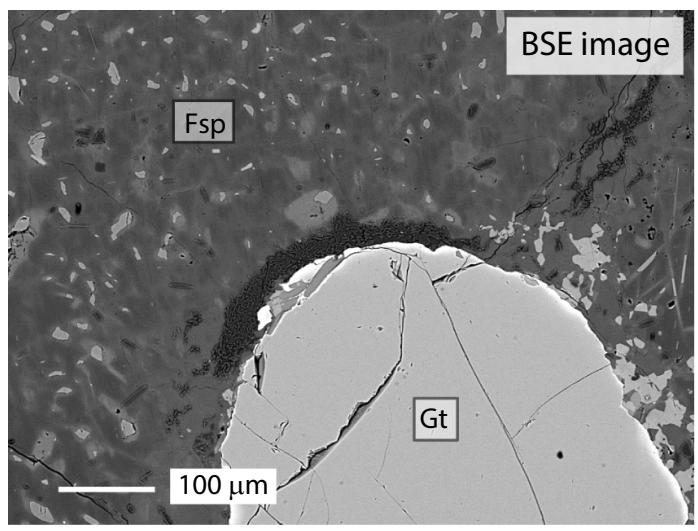

(f)

indicated in a, multiplied by a factor used as fitting parameter and added to a background pressure. $\mathbf{c}$ Stable phase assemblage obtained from the minimization with enlargement in $\mathbf{d}$, fitting the main observations shown with petrographic image $\mathbf{e}$ and BSE image in $\mathbf{f}$. Note that aside from pressure distribution and variation, absolute pressure was also important in fitting the phase assemblage. This gives constraints on the regional pressure 
Fig. 12 Results of Gibbs minimization under constrained pressure in a $2 \mathrm{D}$ domain in the system MnNCMASH. a Same as in Fig. 11a at higher resolution and full model size. Rectangle shows zoom in b. b Zoom into a. Absolute pressure obtained with the same procedure as Fig. 11b. A lower background pressure was used to be consistent with the amphibolite facies P-T conditions estimated in the area (Andersen et al. 1991). White rectangle shows area used in the Gibbs minimization. c Stable phase assemblage estimated for the domain outlined in the white rectangle of $\mathbf{b}$. The fraction of the system at each pressure is approximated using the pressure and corresponding area in $\mathbf{d}$. d Input pressure map obtained from figure $b$ using average pressures over the contoured domains. Thus, five different input pressure constraints were used in this calculation. This averaging procedure allowed calculating equilibrium under pressure constraints in a significantly more complex chemical system (a)

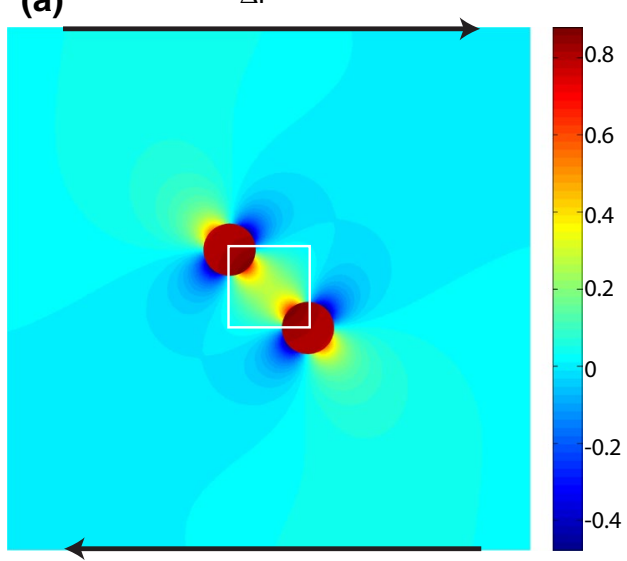

(c)

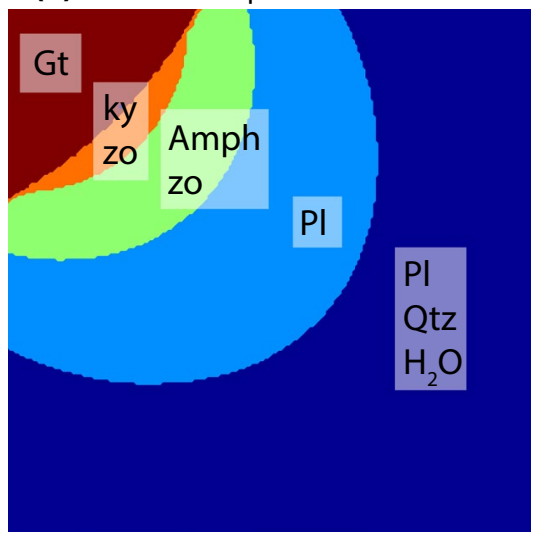

(b)

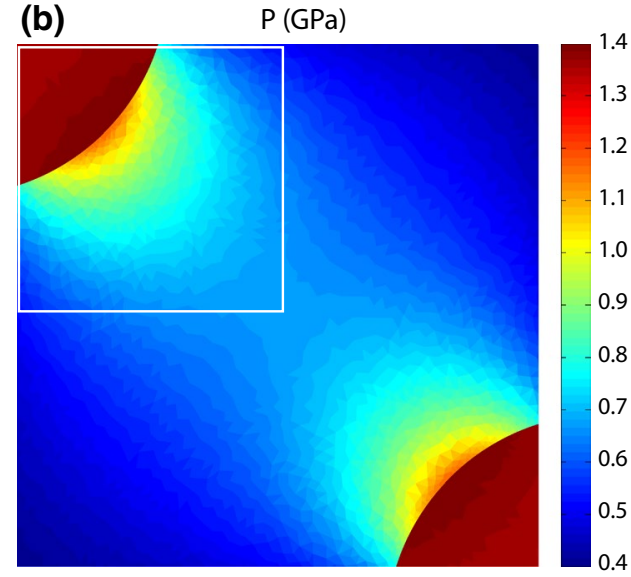

(d)

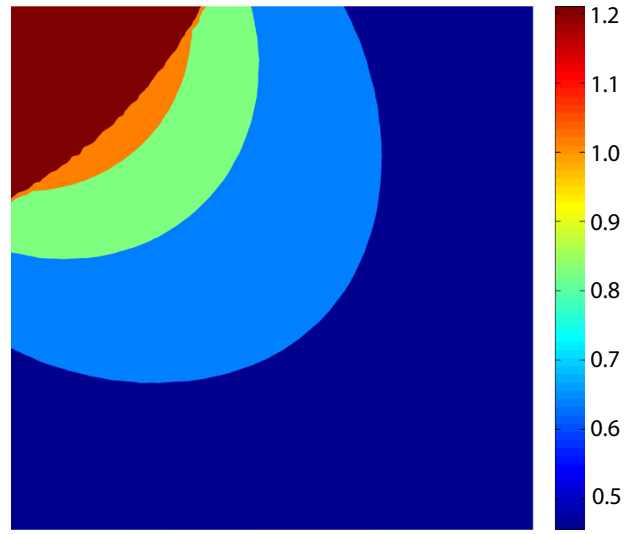

kyanite. Observations of garnet in close relation to kyanite, surrounded by a plagioclase rim, are found in Tajčmanová et al. (2011), as well as garnet crystals in the matrix, isolated from kyanite domains. Similar textures are observed in granulite from the Snowbird tectonic zone (Baldwin et al. 2007) in which garnet crystals have been found with rims of plagioclase.

\section{Two-dimensional multi-component multi-phase systems}

To conclude the applications of the herein described constrained Gibbs minimization method, a two-dimensional pressure map is used as input in the program. One system composition is specified and the pressure computed in a 2D mechanical model. As an example, we have performed a calculation for a texture from the border of a shear zone in granulite from the Bergen Arcs, Norway (Mukai et al. 2014). The first-order observation is a texture that consists of two garnet grains in a matrix of feldspar both capped by an aggregate of kyanite-quartz. We set up a calculation using the finite element method (FEM) for a shear zone with two rigid inclusions (Fig. 11). The analytical and numerical solution for a rigid circular inclusion in simple shear is well known to have high-pressure and low-pressure lobes in the matrix around the inclusion (e.g., Schmid and Podladchikov 2003). If the shape of inclusion is not circular, and depending on the orientation of the inclusion, the pressure can be high in the inclusions with respect to the matrix (Moulas et al. 2014). Additionally, the inclusion may have a positive volume increase relative to the matrix due to reaction which would increase the pressure in the inclusion (Vrijmoed et al. 2009). The result of a FEM calculation for such a system is shown in Fig. 11a, b, and the resulting stable phase assemblage is shown in Fig. 11c and enlarged in Fig. 11d. Comparison to the natural data in Fig. 11e, f shows that the first-order observations are reproduced.

Although the GASP reaction is essentially captured with pure phases and a binary feldspar solution, modeling garnet as a pure end-member is not adequate for natural systems. A related problem is that the absolute pressures in the map are significantly higher than what is expected from other pressure estimates in the area (e.g., Austrheim and Griffin 1985; Andersen et al. 1991). To investigate this, an additional series of calculation was done in the system MnNCFMASH. Clinopyroxene, orthopyroxene, garnet, olivine, spinel, feldspar and amphibole were considered as solution (see caption Fig. 12; Table 2). As system composition, a 
Table 2 Solution models used in the calculations

\begin{tabular}{lll}
\hline Mineral & Solution model & References \\
\hline Ternary feldspar & feldspar & Fuhrman and Lindsley (1988) \\
Ternary feldspar & Fsp(C1) & Holland and Powell (2003) \\
Orthopyroxene & Opx(HP) & Holland and Powell (1996) \\
Garnet & Gt(HP) & Holland and Powell (1998) \\
Olivine & O(HP) & Holland and Powell (1998) \\
Spinel & Sp(HP) & Holland and Powell (1998) \\
Clinopyroxene & Omph(HP) & Holland and Powell (1996) \\
White mica & Mica(CHA) & Coggon and Holland (2002) \\
Amphibole & Amph(DPW) & Dale et al. (2005) \\
Biotite & Bio(TCC) & Tajčmanová et al. (2009) \\
Melt & Melt(HP) & White et al. (2007) \\
\hline
\end{tabular}

mixture was made from $9.5 \%$ garnet (composition of sample 11A2 from Austrheim and Griffin 1985) and $90.5 \%$ feldspar with a composition consisting of $50 \%$ anorthiterich and $50 \%$ anorthite-poor complex feldspar from Mukai et al. (2014). One weight percent $\mathrm{H}_{2} \mathrm{O}$ was added to the system composition as the sample shows also signs of fluid infiltration (Mukai et al. 2014). Due to computational limitations, it was not possible to perform the calculations at the same resolution as Fig. 11. To capture the essentials of the pressure distribution obtained from the mechanical model, the pressure map was divided in average pressure domains. The area of the domains was used to approximate the weight percent of system constrained at each pressure. This means that instead of using all elements from the FEM model only five different pressures were set as input constraints (see Fig. 12d for the discretized pressure map). It is then possible to have garnet stable at the pressure and temperature estimated for the amphibolite facies conditions of the shear zone (Andersen et al. 1991). Also, a kyanite zone in the high-pressure caps around the rigid garnet grains is predicted, although fine quartz-kyanite mixture is not resolved. Instead, there is a prediction of kyanite-zoisite with successive zones of zoisite-amphibole, plagioclase and plagioclase-quartz-water.

Another possibility is that the rigid garnet inclusions are not in equilibrium but are instead fractionated from the matrix. For this case, garnet (and its pressure) was subtracted from the system, and an equilibrium prediction for only the matrix between the rigid inclusions is obtained (Fig. 13). The mechanical model is this case has only rigid non-reacting inclusions. Again the main characteristics are reproduced with a kyanite mixture (with zoisite and some garnet) at the high-pressure caps around the rigid inclusion, and successive zones at lower pressure away from the inclusion containing zoisite, zoisite-plagioclase, plagioclase and plagioclase-quartz-water where pressure variations have nearly vanished. Amphibole is not predicted in contrast to Fig. 12, which is most likely due to the fact that $\mathrm{Mg}-\mathrm{Fe}$ in rigid garnet inclusions were fractionated from the system. These calculations show the difference in global equilibrium and partial disequilibrium (fractionated) under a pressure gradient. To determine which of the models fits the observations better, a detailed microstructural and mineral-chemical study of target areas of thin sections in these rocks is needed.

Another interesting observation is the occurrence of kyanite-quartz or kyanite-zoisite aggregates in cracks (e.g., upper right corner of BSE image in Fig. 11f). To investigate this, we modified the aspect ratio of one weak inclusion in the mechanical model to obtain a strongly elliptical inclusion that captures the essential features of a crack (i.e., a weak zone with an infinite aspect ratio). Under certain orientations with respect to the shear deformation, the pressure in the crack is higher than the matrix (e.g., Moulas et al. 2014). As system composition, plagioclase with composition of $\mathrm{An}_{50}$ is used with 1 weight percent water. The prediction of the thermodynamic equilibrium shows the stability of kyanite-zoisite in the crack, whereas plagioclase, quartz and water are stable in the matrix. Thus, a crack with a certain orientation with respect to the shear deformation can fit the kyanite-zoisite aggregates observed by Mukai et al. (2014) in some cracks in an equilibrium sense.

\section{Discussion}

The presented Gibbs minimization approach provides a tool to predict the equilibrium phase assemblage and concentration in geological systems under a pressure gradient. It is a forward modeling tool that can be used to investigate the potential of explaining observations with pressure variations in space while in thermodynamic equilibrium. This is complementary to already existing techniques to find the pressure (and temperature) variations of rock in time. For example, mineral zoning is commonly used to derive the P-T path; but also phase assemblages are useful by studying inclusions and interpreting phase assemblages and textures in terms of $P-T$ evolution in time (Spear and Selverstone 1983; Gaidies et al. 2008; Caddick et al. 2010; Lanari et al. 2014; Vrijmoed and Hacker 2014).

Confidence in the method is gained by generating conventional phase diagrams (i.e., phases at equal pressure) and comparing them to output from existing software (Perple_X, THERMOCALC). By obtaining similar Gibbs energies and identical phase diagrams, errors resulting from input Gibbs energy of phases or the minimization algorithm are excluded. Tajčmanová et al. (2014) deduced the pressure gradient from measured concentration along a profile across a plagioclase rim surrounding kyanite. To 
Fig. 13 Results of Gibbs minimization under constrained pressure in a $2 \mathrm{D}$ domain in the system NCMASH with garnet composition in the rigid inclusions subtracted from the system. This represents a situation in which the rigid garnet inclusions are not in equilibrium with the matrix. The main difference is the absence of amphibole in this calculation compared to including garnet in the equilibrium in Fig. 12. a Dimensionless pressure variations $\left(\Delta \mathrm{P}^{*}\right)$ from the FEM model with rigid non-reactive circular inclusions. b Zoom in of a. c Stable phase assemblage for averaged pressure distribution in $\mathbf{d}$. $\mathbf{d}$ Averaged pressure distribution in the domain outlined in figure $b$. See also caption of Fig. 12
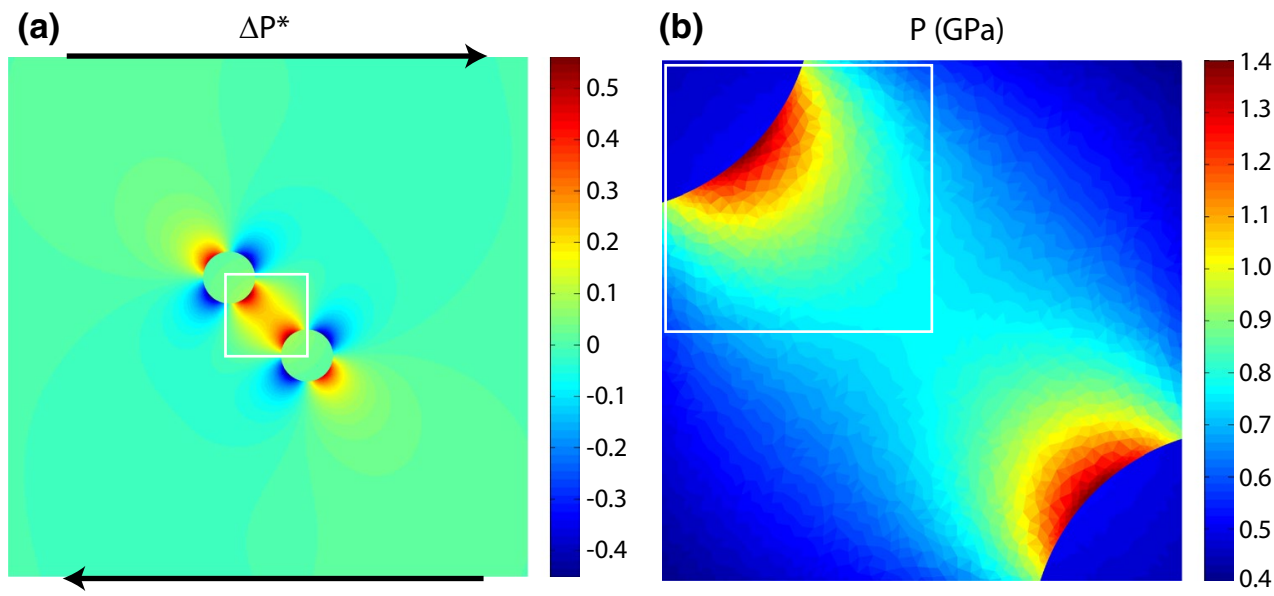

(c) stable phases

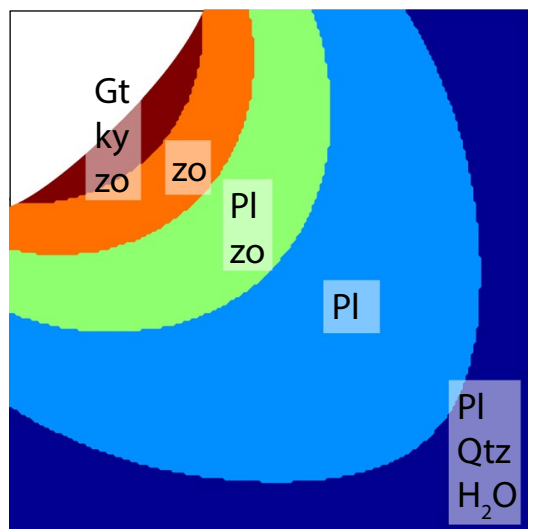

(d)

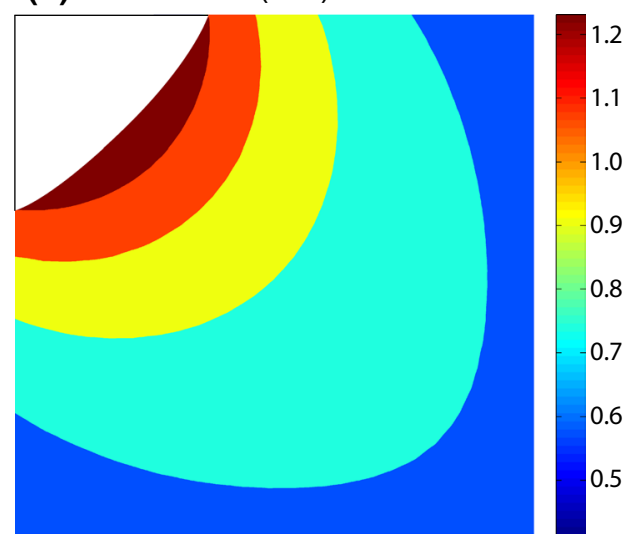

this end, they developed a geobarometer based on chemical potentials. From the thermodynamic point of view, perhaps the most striking result is the opposite trend compared to what is expected from a phase diagram. In a conventional $P-T$ section for the relevant rock composition, the $\mathrm{Ab}$ content increases with pressure. However, in Tajčmanová et al. (2014), An content is highest at the contact with the high-pressure kyanite inclusion and decreases toward the low-pressure matrix. The currently presented Gibbs energy method delivers the same result, thereby increasing the confidence in the geobarometer of Tajčmanová et al. (2014).

Both equilibrium methods (barometry and Gibbs minimization) are used to deduce pressure variations in Opx of the Svartberget UHP garnet-peridotite from the WGR, Norway (Vrijmoed et al. 2006, 2013). Again, both methods consistently predict opposite results compared to what is expected from a conventional phase diagram or garnetorthopyroxene barometry. Bowl-shaped Al zoning (low concentration in the core) is predicted to result from highest pressure along rims and cracks of the Opx grains while the core composition corresponds to low pressure. On a larger scale, this is observed in the pyroxenite and garnetite veins crosscutting the Svartberget body. The mineralogy and geothermobarometric results indicate higher pressures than the wall rock peridotite (Vrijmoed et al. 2006, 2008). Vrijmoed et al. (2009) proposed a conceptual model to account for these pressure variations on the outcrop scale; however, the model would also fit the smaller-scale pressure variations with highest pressure along rims and cracks inferred from the $\mathrm{Al}$ zoning in Opx.

Separation of discrete mono- or bi-mineralic zones can be a result of disequilibrium processes such as infiltration or diffusion metasomatic zoning (Korzhinskii 1970), as well as disequilibrium diffusion-controlled rim growth leading to corona structures (Ashworth et al. 1992). However, it is shown here that pressure gradients also have the potential to result in such discrete mineralogical zoning and complete separation into single-phase regions. Figure 10 shows that when pressure is homogeneous multi-phase regions are predicted, similar to conventional phase diagram calculations assuming equal pressure in all phases. It must be noted that spatial information does not enter the Gibbs minimization method; therefore, plotting of phases is independent from the prediction of stable phase assemblage and composition. When combined with models predicting spatial distribution of pressure and assuming 
Fig. 14 Results of Gibbs minimization under constrained pressure in a weak strongly elliptical inclusion approximating a fracture for a system composition consisting of feldspar $\left(\mathrm{An}_{50}\right)$ and one weight percent water. High-pressure phases are predicted in the fracture reflecting the pressure increase due to decrease in differential stress with respect to the matrix. See Moulas et al. (2014) for full analysis of pressure in elliptical inclusions. See caption Fig. 12
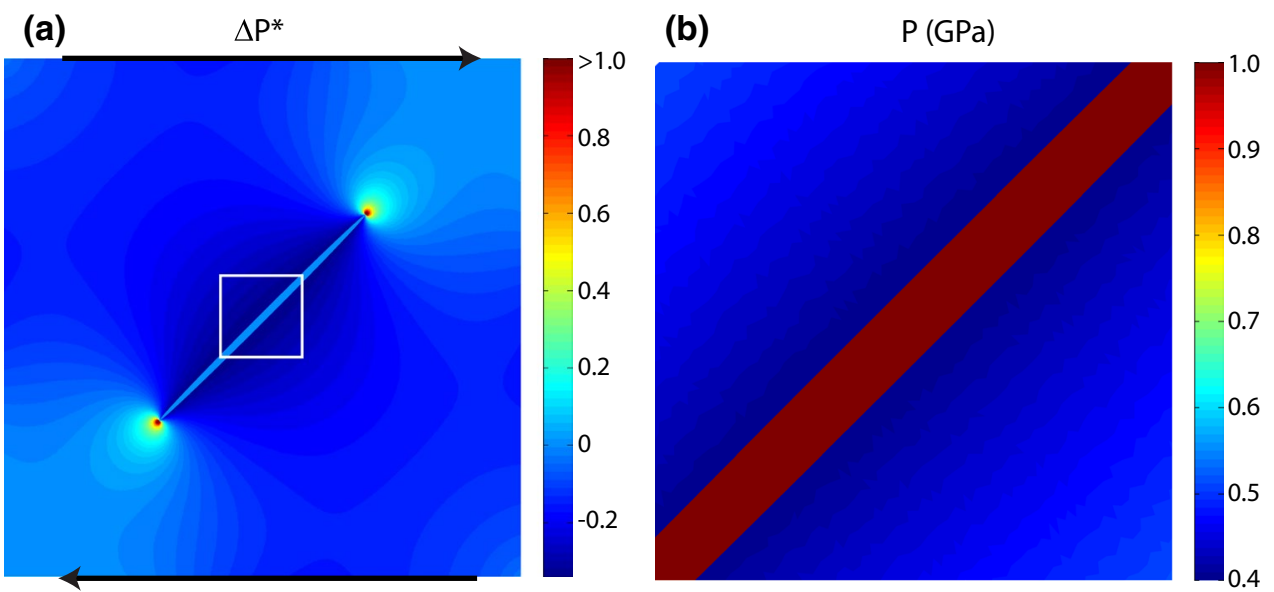

(c) stable phases

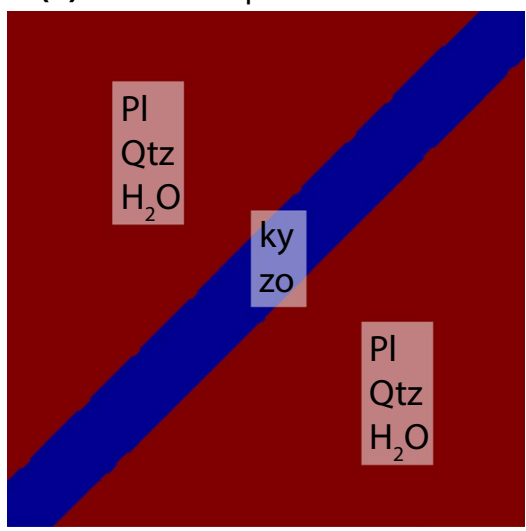

(d) $\mathrm{P}(\mathrm{GPa})$

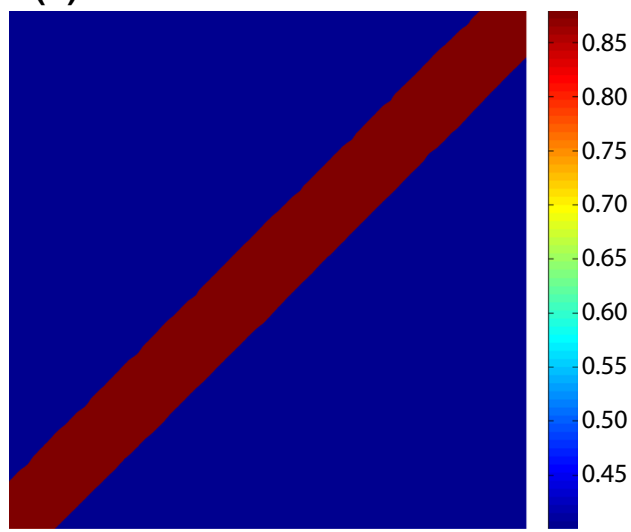

equilibrium, the thermodynamic prediction can be plotted in space. The uniqueness of chemical equilibrium is guaranteed by the global minimization for the input pressure and system composition constraints, because the algorithm only converges when it found the global minimum under the constraints. The phase distribution for a given pressure distribution in space may be a function of initial conditions or perhaps processes such as nucleation. As nucleation may also depend on pressure, perhaps where phases nucleate may be partially controlled by small variations in pressure.

The work presented here raises new questions and is intended to promote new directions in research that may answer them. The presented equilibrium methods have some limits of applicability:

1. Results become unreliable when temperature becomes significantly low and/or time scale becomes too short to reach equilibrium by diffusion. Predictions from experimental values for diffusion coefficients in combination with geochronology may be used to evaluate whether significant diffusion is expected to have occurred.

2. Pressure variations need to be sustained on the time scale of the diffusion. Residual pressure has been measured in a number of cases, and thus, there seem to be situations that pressure variations outlast any reaction or diffusion process.

\section{Inferring spatial pressure variation from phase assemblage and chemical zoning as an inverse problem}

The method presented here is incomplete since the pressure "fractionation" is an input rather than a model prediction. The method is formulated as a forward method. Therefore, there is formally no difference between assuming equal pressure as input as is commonly done in petrology, and input of multiple pressures. That pressure in metamorphic rocks can be heterogeneous is supported by theory and observations reviewed in the introduction. Pressure "fractionation" is arbitrary specified using mass fractions. Once the stable phase assemblage and density are computed, the mass constraints can be post-processed into volumetric constraints and arbitrarily and non-uniquely distributed in space. An inverse method that would predict pressure from measured concentration and phase distribution in a microstructure would have to consider a fully coupled (thermo-) mechanical-reactive model by which pressure obtained from a mechanical model is consistent with material and 
rheological properties of the predicted phases in thermodynamic equilibrium. However, a correct computation method of thermodynamic equilibrium under a pressure gradient is a prerequisite to build such an inverse method.

\section{Geodynamic implications}

Current progress in research on pressure variations in metamorphic rocks indicates the maintenance of these pressures on the geological time scale. It becomes therefore challenging to decide which pressure corresponds to the regional pressure (i.e., should we always take the highest pressure found in single inclusions). The presented method can be used to find the pressure distribution that fits geological observations, but also the absolute pressures are important in this fit, and hence, this can provide insights into the regional pressure value that fits the observations.

The case of plagioclase zoning around kyanite is problematic because phase diagram calculations indicate formation of plagioclase around kyanite during decompression, consistent with geodynamic reconstructions of the area, but zoning in these plagioclase rims points to the opposite $P-T$ path. It can thus be explained either as disequilibrium features (i.e., with chemical potential gradients, Stipska et al. 2010) or with equilibrium under a pressure gradient (Tajčmanová et al. 2014) in which case it is consistent with experimentally determined diffusion coefficients in addition to fitting the geodynamic history of the region.

\section{Conclusion}

The following conclusions can be drawn:

1. Chemical zoning and phase assemblages indicating variation in pressure may reflect spatial pressure variations at equilibrium rather than recording pressure evolution in time due to disequilibrium. The method presented here can be used complementary to existing inverse $P-T$ path modeling techniques for cases where equilibrium is expected to be reached.

2. Considering pressure variations in equilibrium thermodynamic calculations may lead to opposite zoning trends to what is expected from a conventional phase diagram. It is concluded that when pressure variation is known to exist (e.g., by direct measurements), conventional phase diagrams are inappropriate to use in assessing equilibrium.

3. The chemical potential-based barometry and Gibbs minimization approach deliver the same results and strengthen the confidence in the reliability of both the barometry and the minimization technique.
4. Gibbs minimization extends the chemical potentialbased equilibrium under pressure variations in singlephase binary (Tajčmanová et al. 2014) to multi-phase, multi-component systems. It may be used to develop barometric methods for multi-component, multi-phase systems.

5. Equilibrium under pressure gradients may result in separation into single-phase regions.

Acknowledgments The work presented here profited from discussions with various people starting at Physics of Geological Processes (PGP) in 2005 and from discussions with L. Tajčmanová and E. Moulas at ETH Zurich. Financial support was provided by Faculty of Earth Sciences, University of Lausanne, and by ERC starting Grant 335577 to Lucie Tajčmanová.

\section{Appendix 1: Gibbs energy calculation}

\section{Pure phases}

Partial molar Gibbs energy $\left(g^{0}\right)$ for mineral and liquid endmembers is generalized as a linear combination of the independent (idp) set of end-members in the internally consistent thermodynamic data set of Holland and Powell (1998), hereafter referred to as HP98 data set. Enthalpy of formation of ordered end-members (Holland and Powell 1996) and energies for fictive end-members following from application of Darken's Quadratic Formalism (Powell 1987; Holland and Powell 1992; Will and Powell 1992) are generalized by a single DQF parameter:

$g^{0}=\sum_{i d p=1}^{n i d p} v_{i d p} \cdot \Delta G_{i d p}^{0}+\mathrm{DQF}$

For the independent end-members in the HP98 data set, the stoichiometric coefficient and the DQF parameter are 1 and 0, respectively. Partial molar Gibbs energy of these endmembers is calculated following standard formulation (Spear 1993), with the addition of two excess Gibbs energy terms for phases treated to a Landau model (Holland and Powell 1998):

$$
\begin{aligned}
& \Delta G^{0}=\underbrace{\Delta_{f} H_{\text {ref }}+\int_{T_{\text {ref }}}^{T} C_{p} \cdot \mathrm{d} T+\int_{P_{\text {ref }}}^{P} V \cdot \mathrm{d} P}_{H}-T \cdot \underbrace{\left(S_{\text {ref }}+\int_{T_{\text {ref }}}^{T} \frac{C_{p}}{T} \cdot \mathrm{d} T\right)}_{S} \\
& +\Delta G_{\text {exc }}+\Delta G_{\text {landau }}
\end{aligned}
$$

Heat capacity is given by the polynomial in the caption of Table 5 in Holland and Powell (1998):

$C_{p}=a+b \cdot T+c \cdot T^{2}+d \cdot T^{-1 / 2}$ 
Volume at reference pressure (1 bar) and elevated temperatures is given by Holland and Powell (1998):

$V_{1, T}=V_{\text {ref }} \cdot\left[1+a^{0} \cdot\left(T-T_{\text {ref }}\right)-20 \cdot a^{0} \cdot\left(\sqrt{T}-\sqrt{T_{\text {ref }}}\right)\right]$

Volume at elevated pressure is modeled with the Murnaghan equation of state rearranged for volume:

$V=\frac{V_{1, T}}{\left(\frac{4 \cdot P}{k_{T}+1}\right)^{1 / 4}}$

The bulk modulus is given by Holland and Powell (1998):

$k_{T}=k_{\mathrm{ref}} \cdot\left(1-1.5 \cdot 10^{-4} \cdot\left(T-T_{\mathrm{ref}}\right)\right)$

\section{Landau model excess energy}

Phases undergoing order-disorder or lambda heat capacity anomalies are treated with a Landau model (Holland and Powell 1990, 1998). The excess Gibbs energy term related to this model is calculated from:

$\Delta G_{\mathrm{exc}}=h_{\mathrm{ref}}^{\prime}-T \cdot s_{\mathrm{ref}}^{\prime}+\int_{P_{\mathrm{ref}}}^{P} v_{T}^{\prime} \cdot \mathrm{d} P$

With the enthalpy and entropy at reference conditions given in Eqs. (16) and (17):

$h_{\mathrm{ref}}^{\prime}=S_{\max } T_{c}^{0} \cdot\left(Q_{\mathrm{ref}}^{2}-\frac{1}{3} \cdot Q_{\mathrm{ref}}^{6}\right)$

$s_{\text {ref }}^{\prime}=S_{\text {max }} \cdot Q_{\text {ref }}^{2}$

The volume integral is evaluated again with the Murnaghan equation of state using the volume at reference pressure and elevated temperature from:

$v_{T}^{\prime}=\frac{V_{\mathrm{max}} \cdot Q_{\mathrm{ref}}^{2}}{V_{\mathrm{ref}}} \cdot V_{1, T}$

The Landau excess energy is then obtained with:

$\Delta G_{\text {Land }}=S_{\max }\left(\left(T-T_{c}\right) \cdot Q^{2}+\frac{1}{3} \cdot T_{c} \cdot Q^{6}\right)$

This term is added only at temperatures below the critical temperature $T_{c}$ :

$T_{c}=T_{c}^{0}+\frac{V_{\max }}{S_{\max }} \cdot\left(P-P_{\text {ref }}\right)$

The order parameter $Q$ (and $Q_{\text {ref }}$ evaluated at reference conditions) is calculated as:
$Q=\left(1-\frac{T}{T_{c}}\right)^{1 / 4}$

Parameters needed in Eqs. (10)-(21) are: $\Delta_{f} H_{\text {ref }}, S_{\text {ref }}, a$, $b, c, d, V_{\mathrm{ref}}, a^{0}, k_{\mathrm{ref}}, T c^{0}, S_{\max }$ and $V_{\max }$. Most updated values of these parameters are found in the tc-ds55 file bundled with the most recent version of THERMOCALC (http:// www.metamorph.geo.uni-mainz.de/thermocalc). Reference conditions are $298.15^{\circ} \mathrm{K}$ at 1 bar. See Table 3 for a complete list of symbols and parameters used in "Appendix 1".

\section{Ordered and fictive end-members}

Stoichiometric coefficients $\left(v_{i d p}\right)$ and name of independent end-members in Eq. 9 are found in activity-composition $(a-x)$ files bundled with THERMOCALC or individually downloadable from http://www.metamorph.geo.uni-mainz. de/thermocalc. The DQF parameter capturing both the DQF energy of fictive end-members and the enthalpy of reactions forming ordered end-members is given as:

$\mathrm{DQF}=a_{\mathrm{DQF}}+b_{\mathrm{DQF}} \cdot T+c_{\mathrm{DQF}} \cdot P$

Parameters $a_{\mathrm{DQF}}, b_{\mathrm{DQF}}$ and $c_{\mathrm{DQF}}$ are found in the lines below the stoichiometric coefficients in the same $\mathrm{a}-\mathrm{x}$ files.

\section{Solid solutions}

The partial molar Gibbs energy of mixing in solid solutions and melts consist of a mechanical (mech), ideal (id), and a non-ideal (nid) part:

$g=g_{\text {mech }}+g_{\text {id }}+g_{\text {nid }}$

Mechanical mixing Gibbs energy consists of a linear combination of the total number $(n p)$ of end-member Gibbs energies in the solution, obtained from Eq. (9) above, multiplied by its proportion $p$.

$g_{\text {mech }}=\sum_{i p=1}^{n p} g_{i p}^{0} \cdot p_{i p}$

Ideal mixing Gibbs energy, or configurational energy, is obtained from the sum of crystallographic site fractions following Stirling's approximation (see also the Appendix in Tajčmanová et al. 2009).

$g_{i d}=T \cdot\left(R \cdot \sum_{i z=1}^{n z} m_{i z} \cdot z_{i z} \cdot \ln \left(z_{i z}\right)-\sum_{i p=1}^{n p} s_{i p}^{0} \cdot p_{i p}\right)$

Definition of certain solution models results in nonzero site fractions for some end-members leading to nonzero configurational entropy for the pure end-member. This is corrected for by the last sum in Eq. (25), because in 
Table 3 Description of symbols and parameters used in the presented equations in the Appendix 1

\begin{tabular}{|c|c|c|}
\hline Symbol & Description & Source \\
\hline$R$ & Universal gas constant & \\
\hline$T_{\text {ref }}$ & Temperature at reference conditions & $298.15 \mathrm{~K}$ \\
\hline$P_{\text {ref }}$ & Pressure at reference conditions & 1 bar \\
\hline \multicolumn{3}{|c|}{ Pure phases (end-members, partial molar quantities) } \\
\hline$\Delta_{f} H_{\text {ref }}$ & Enthalpy of formation from the elements & tc-ds55 \\
\hline$S_{\text {ref }}$ & Entropy & tc-ds55 \\
\hline$a, b, c, d$ & Heat capacity parameters & tc-ds55 \\
\hline$V_{\text {ref }}$ & Volume at reference conditions & tc-ds55 \\
\hline$a^{0}$ & Thermal expansion coefficient at reference conditions & tc-ds55 \\
\hline$k_{\text {ref }}$ & Compressibility at reference conditions & tc-ds55 \\
\hline$S_{\max }$ & Entropy at reference conditions for use in Landau formulation & tc-ds55 \\
\hline$T_{c}^{0}$ & Critical Landau transition temperature at reference pressure & tc-ds55 \\
\hline$V_{\max }$ & Volume at reference conditions for use in Landau formulation & tc-ds55 \\
\hline$V_{l, T}$ & Partial molar volume at reference pressure & calc \\
\hline$g^{0}$ & Partial molar Gibbs energy & calc \\
\hline$V$ & Volume & calc \\
\hline$C_{p}$ & Heat capacity & calc \\
\hline$k_{T}$ & Compressibility at reference pressure & calc \\
\hline$\Delta G_{\mathrm{exc}}$ & Excess Gibbs energy for Landau formulation & calc \\
\hline$\Delta G_{\text {landau }}$ & Landau Gibbs energy & calc \\
\hline$h_{\text {ref }}^{\prime}$ & Enthalpy at reference conditions treated with Landau formulation & calc \\
\hline$s_{\text {ref }}^{\prime}$ & Entropy at reference conditions treated with Landau formulation & calc \\
\hline$v_{T}^{\prime}$ & Molar volume at reference pressure treated with Landau & calc \\
\hline$Q_{\text {ref }}$ & Landau order-disorder parameter at reference conditions & calc \\
\hline$T_{c}$ & Critical Landau transition temperature & calc \\
\hline$Q$ & Landau order-disorder parameter & calc \\
\hline DQF & Darken's Quadratic Formalism parameter or $\Delta H$ of ordering reaction & calc \\
\hline$a_{\mathrm{DQF}}, b_{\mathrm{DQF}}, c_{\mathrm{DQF}}$ & DQF parameters & ax \\
\hline \multicolumn{3}{|l|}{ Solid solutions } \\
\hline$\varepsilon$ & Valance & \\
\hline$m$ & Site multiplicity & ax \\
\hline$W_{0}, W_{T}, W_{P}$ & Margules parameter & ax \\
\hline$\alpha_{0}, \alpha_{T}, \alpha_{P}$ & van Laar size parameter (for asymmetric formalism) & $\mathrm{ax}$ \\
\hline$n O$ & Number of oxygens for charge balance in solution model & ax \\
\hline$v_{i Q, i z}$ & Coefficient in front of site fraction in $i Q$ th equation of order variable & $\mathrm{ax}$ \\
\hline$v_{i c, i z}$ & Coefficient in front of site fraction in $i c$ th equation of compositional variable & ax \\
\hline$v_{i e x, i z}$ & Coefficient in front of site fraction in iexth equation of extra constraints & ax \\
\hline$v_{i n d, i p}^{p}$ & Coefficient in front of proportion in indth equation of site fractions & ax \\
\hline$v_{i d p}$ & Coefficient for independent end-member energy for ordered and fictive & ax \\
\hline$g_{\text {mech }}$ & Partial molar Gibbs energy of mechanical mixing & calc \\
\hline$g_{i d}$ & Partial molar Gibbs energy of ideal mixing & calc \\
\hline$g_{\text {nid }}$ & Partial molar Gibbs energy of non-ideal mixing & calc \\
\hline$g_{i}$ & Partial molar Gibbs energy of phase i & calc \\
\hline$n p$ & Number of end-members & calc \\
\hline$n z$ & Number of site fractions & calc \\
\hline$p$ & Proportion of end-member in solution & calc \\
\hline$n e_{\text {is }}$ & Number of elements for the $i s$ th site & calc \\
\hline$z$ & Site fraction & calc \\
\hline$s^{0}$ & Mixing entropy for pure end-members in solution & calc \\
\hline$z^{0}$ & Site fraction of pure end-member in solution & calc \\
\hline$W^{*}$ & Asymmetric Margules parameter & calc \\
\hline$\phi$ & Asymmetric proportion of end-member in solution & calc \\
\hline
\end{tabular}

tc-ds55 = THERMOCALC dataset 5.5; calc $=$ calculated $; \mathrm{ax}=$ THERMOCALC $\mathrm{a}-\mathrm{x}$ model file 
principle pure phases do not contribute to ideal mixing energy. The configurational entropy for the pure end-members in the solution is calculated from site fractions of pure end-member $\left(z^{0}\right)$ :

$s_{i p}^{0}=R \cdot \sum_{i z=1}^{n z} m_{i z} \cdot z_{i p, i z}^{0} \cdot \ln \left(z_{i p, i z}^{0}\right)$

For example, the anorthite end-member in ternary feldspar is defined as having the tetrahedral site filled half with $\mathrm{Al}$ and the other half with $\mathrm{Si}$, so that both site fractions ( $\mathrm{Si}$ and $\mathrm{Al}$ on the tetrahedral site) are half. An equivalent approach for chemical potentials is described in Powell and Holland (1993).

Non-ideal mixing Gibbs energy is generalized to account for ternary interaction parameters and asymmetric Van Laar formulation (Holland and Powell 2003):

$g_{\text {nid }}=\sum_{i w=1}^{n w} W_{i w}^{*} \cdot \prod_{i p=1}^{n i} \varphi_{w i_{i p, i w}}$

The Margules parameters $W_{i w}^{*}$ are multiplied by the product of proportions $\varphi$ corresponding to the $i w$ th interaction parameter. The indices of $\varphi$ for each $i w$ th interaction parameter are stored in a matrix "wi." This matrix has $n w$ number of Margules parameters and $n i$ number of endmember indices. The number of multiplied proportions $(n i)$ is depending on the solution model. Usually the Margules parameters are binary interaction, but for feldspar they are ternary interaction parameters. This corrected Margules parameter $W_{i w}^{*}$ is obtained from Margules parameters $W_{i w}$ fitted in experiments (e.g., found in literature) multiplied by proportions of interacting end-members and corrected by a size parameter $(\alpha)$ :

$W_{i w}^{*}=W_{i w} \cdot \frac{n i \cdot\left(\sum_{k=1}^{n p} \alpha_{k} \cdot p_{k}\right)}{\sum_{i p=1}^{n i} \alpha_{w i} i_{i p, i w}}$

The asymmetric proportion $\varphi$ of the $i$ th end-member is found from:

$\varphi_{i}=\frac{p_{i} \cdot \alpha_{i}}{\sum_{j=1}^{n p} p_{j} \cdot \alpha_{j}}$

Both the Margules and $\alpha$ parameters are in principle pressure and temperature dependent and parameterized as:

$W=W_{0}+W_{T} \cdot T+W_{P} \cdot P$

$\alpha=\alpha_{0}+\alpha_{T} \cdot T+\alpha_{P} \cdot P$

Values for $\alpha_{0}, \alpha_{T}, \alpha_{P}$ and $W_{0}, W_{T}, W_{P}$ are found in literature describing solution models, from a-x files bundled with THERMOCALC or from the solution_model.dat file packaged with Perple_X.

\section{Site speciation}

Finding the site fractions as function of mineral compositions is done by setting up a linear system of equations. The first set of equations is found by the definition that site fractions on each site sum up to 1 . This gives ns (number of sites) equations. For each isth site, the equation is:

$\sum_{i=1}^{n z} z_{i s, i z} \cdot v_{i s, i z}=1$

The second set of equations is given by the definition of compositional variables:

$\sum_{i z=1}^{n z} z_{i z} \cdot v_{i c, i z}=C_{i c}$

In case of order-disorder in a mineral, for each ordered end-member, an extra equation is required that defines the order parameter.

$\sum_{i z=1}^{n z} z_{i z} \cdot v_{i Q, i z}=Q_{i Q}$

Then, any extra assumptions form additional equations (e.g., equal distribution of an element over different sites):

$\sum_{i z=1}^{n z} z_{i z} \cdot v_{i e x, i z}=0$

If the system of equations is not closed, a charge balance equation can be added to ensure electro-neutrality:

$\sum_{i z=1}^{n z} z_{i z} \cdot m_{i z} \cdot \varepsilon_{i z}=2 \cdot n O$

After the site fractions have been found as function of compositional variables, the proportions of endmembers as function of site fractions can be solved from the obtained matrix of site fractions and proportions of end-members.

The first equation is always the constraint that proportions sum up to 1 :

$\sum_{i p=1}^{n p} p_{i p}=1$

For the remaining equations, the independent set of equations of site fraction as function of proportion is chosen:

$z_{\text {ind }}=\sum_{i p=1}^{n p} p_{i p} \cdot v_{\text {ind }, i p}^{p}$ 


\section{Appendix 2: Site speciation and proportion calculation example}

\section{Clinoamphibole}

For clinoamphibole from Diener et al. (2007) (closely resembling orthoamphibole from the same authors), identical to cAmph(DP) or cAmph(DP2) in Perple_X, the crystallography can be tabulated as:

\begin{tabular}{|c|c|c|c|c|c|c|c|c|c|c|c|c|c|c|}
\hline \multirow{3}{*}{$\begin{array}{l}\text { Crystallography } \\
\text { Multiplicity }\end{array}$} & \multicolumn{2}{|c|}{ Site 1} & \multicolumn{2}{|c|}{ Site 2} & \multicolumn{4}{|c|}{ Site 3} & \multicolumn{4}{|c|}{ Site 4} & \multicolumn{2}{|c|}{ Site 5} \\
\hline & A & & $\mathrm{M}_{13}$ & & $\mathrm{M}_{2}$ & & & & $\mathrm{M}_{4}$ & & & & $\mathrm{~T}_{1}$ & \\
\hline & 1 & & 3 & & 2 & & & & 2 & & & & $4(1$ & \\
\hline Site fraction & $z_{1}$ & $z_{2}$ & $z_{3}$ & $z_{4}$ & $z_{5}$ & $z_{6}$ & $z_{7}$ & $z_{8}$ & $z_{9}$ & $z_{10}$ & $z_{11}$ & $z_{12}$ & $z_{13}$ & $z_{14}$ \\
\hline Charge & 0 & 1 & 2 & 2 & 2 & 2 & 3 & 3 & 2 & 2 & 2 & 1 & 4 & 3 \\
\hline Element & $\mathrm{V}$ & $\mathrm{Na}$ & $\mathrm{Mg}$ & $\mathrm{Fe}$ & $\mathrm{Mg}$ & $\mathrm{Fe}$ & $\mathrm{Al}$ & $\mathrm{Fe}^{3}$ & $\mathrm{Ca}$ & $\mathrm{Mg}$ & $\mathrm{Fe}$ & $\mathrm{Na}$ & $\mathrm{Si}$ & $\mathrm{Al}$ \\
\hline
\end{tabular}

The brackets indicate a multiplicity which is employed by Diener et al. (2007) to calculate ideal mixing energy rather than using the actual site multiplicity (see also comments in solution_model.dat file from the current version of Perple_X software package). For charge balance in equations below, the correct multiplicity (4) is used.

From this the set of equations, to find site fraction can be written:

$$
\begin{aligned}
& z_{1}+z_{2} \quad=1 \\
& z_{3}+z_{4} \quad=1 \\
& z_{5}+z_{6}+z_{7}+z_{8} \quad=1 \\
& z_{9}+z_{10}+z_{11}+z_{12}=1 \\
& z_{13}+z_{14}=1 \\
& z_{2}+6 z_{3}+6 z_{4}+4 z_{5}+4 z_{6}+6 z_{7}+6 z_{8}+4 z_{9}+4 z_{10}+4 z_{11}+2 z_{12}+16 z_{13}+12 z_{14}=30 \\
& 2 z_{7}+4 z_{14}=\mathrm{Al} \\
& 3 z_{4}+2 z_{6}+2 z_{11}=\mathrm{Fe} \\
& 3 z_{3}+2 z_{5}+2 z_{10} \quad=M g \\
& 2 z_{9} \quad=\mathrm{Ca} \\
& z_{2} \\
& 2 z_{12} \quad=N a \\
& 2 z_{8} \quad=\mathrm{Fe}^{3+} \\
& \begin{aligned}
z_{4} & =z_{\mathrm{Fe}}^{\mathrm{M} 13} \\
z_{6} & =z_{\mathrm{Fe}}^{\mathrm{M} 2}
\end{aligned}
\end{aligned}
$$


The last two equations to close the system are unknown site fractions that need to be varied independently. They function like an order-disorder parameter such as Q's used in THERMOCALC formulations (Eq. 34).

Solving this for site fraction $z$ gives:

$z_{1}=\frac{9}{2}-\frac{3}{4} \mathrm{Na}-\frac{1}{2} \mathrm{Mg}-\frac{1}{2} \mathrm{Ca}-\frac{1}{2} \mathrm{Fe}-\frac{1}{4} \mathrm{Fe}^{3+}-\frac{1}{4} \mathrm{Al}$

$z_{2}=\frac{3}{4} \mathrm{Na}-\frac{7}{2}+\frac{1}{2} \mathrm{Mg}+\frac{1}{2} \mathrm{Ca}+\frac{1}{2} \mathrm{Fe}+\frac{1}{4} \mathrm{Fe}^{3+}+\frac{1}{4} \mathrm{Al}$

$z_{3}=1-z_{\mathrm{Fe}}^{\mathrm{M}_{13}}$

$z_{4}=z_{\mathrm{Fe}}^{\mathrm{M}_{13}}$

$z_{5}=-\frac{3}{4}+\frac{1}{4} \mathrm{Mg}+\frac{1}{4} \mathrm{Ca}+\frac{1}{4} \mathrm{Fe}-\frac{1}{8} \mathrm{Fe}^{3+}-\frac{1}{8} \mathrm{Al}+\frac{1}{8} \mathrm{Na}-z_{\mathrm{Fe}}^{\mathrm{M}_{2}}$

$z_{6}=z_{\mathrm{Fe}}^{\mathrm{M}_{2}}$

$z_{7}=\frac{7}{4}-\frac{1}{4} \mathrm{Mg}-\frac{1}{4} \mathrm{Ca}-\frac{1}{4} \mathrm{Fe}-\frac{3}{8} \mathrm{Fe}^{3+}+\frac{1}{8} \mathrm{Al}-\frac{1}{8} \mathrm{Na}$

$z_{8}=\frac{1}{2} \mathrm{Fe}^{3+}$

$z_{9}=\frac{1}{2} \mathrm{Ca}$

$z_{10}=-\frac{3}{4}+\frac{3}{2} z_{\mathrm{Fe}}^{\mathrm{M}_{13}}+z_{\mathrm{Fe}}^{\mathrm{M}_{2}}-\frac{1}{4} \mathrm{Fe}-\frac{1}{8} \mathrm{Na}+\frac{1}{4} \mathrm{Mg}-\frac{1}{4} \mathrm{Ca}$

$+\frac{1}{8} \mathrm{Fe}^{3+}+\frac{1}{8} \mathrm{Al}$

$z_{11}=-\frac{3}{2} z_{\mathrm{Fe}}^{\mathrm{M}_{13}}-z_{\mathrm{Fe}}^{\mathrm{M}_{2}}+\frac{1}{2} \mathrm{Fe}$

$z_{12}=\frac{7}{4}+\frac{1}{8} \mathrm{Na}-\frac{1}{4} \mathrm{Mg}-\frac{1}{4} \mathrm{Ca}-\frac{1}{4} \mathrm{Fe}-\frac{1}{8} \mathrm{Fe}^{3+}-\frac{1}{8} \mathrm{Al}$

$z_{13}=\frac{15}{8}-\frac{1}{8} \mathrm{Mg}-\frac{1}{8} \mathrm{Ca}-\frac{1}{8} \mathrm{Fe}-\frac{3}{16} \mathrm{Fe}^{3+}-\frac{3}{16} \mathrm{Al}-\frac{1}{16} \mathrm{Na}$

$z_{14}=-\frac{7}{8}+\frac{1}{8} \mathrm{Mg}+\frac{1}{8} \mathrm{Ca}+\frac{1}{8} \mathrm{Fe}+\frac{3}{16} \mathrm{Fe}^{3+}+\frac{3}{16} \mathrm{Al}+\frac{1}{16} \mathrm{Na}$

Substituting the compositional variables ( $\mathrm{Al}, \mathrm{Fe}, \mathrm{Mg}, \mathrm{Ca}$, $\mathrm{Na}$ and $\mathrm{Fe}^{3+}$ ) for each end-member (found in the tc-ds55 database file) and the site fractions for the ordered endmembers ( $\mathrm{a}$ and $\mathrm{b}$ ) gives the site fractions in the table below:

\begin{tabular}{llllllllllllllll}
\hline & & $z_{1}$ & $z_{2}$ & $z_{3}$ & $z_{4}$ & $z_{5}$ & $z_{6}$ & $z_{7}$ & $z_{8}$ & $z_{9}$ & $z_{10}$ & $z_{11}$ & $z_{12}$ & $z_{13}$ & $z_{14}$ \\
\hline tr & $p_{1}$ & 1 & 0 & 1 & 0 & 1 & 0 & 0 & 0 & 1 & 0 & 0 & 0 & 1 & 0 \\
ts & $p_{2}$ & 1 & 0 & 1 & 0 & 0 & 0 & 1 & 0 & 1 & 0 & 0 & 0 & $1 / 2$ & $1 / 2$ \\
parg & $p_{3}$ & 0 & 1 & 1 & 0 & $1 / 2$ & 0 & $1 / 2$ & 0 & 1 & 0 & 0 & 0 & $1 / 2$ & $1 / 2$ \\
gl & $p_{4}$ & 1 & 0 & 1 & 0 & 0 & 0 & 1 & 0 & 0 & 0 & 0 & 1 & 1 & 0 \\
cumm & $p_{5}$ & 1 & 0 & 1 & 0 & 1 & 0 & 0 & 0 & 0 & 1 & 0 & 0 & 1 & 0 \\
grun & $p_{6}$ & 1 & 0 & 0 & 1 & 0 & 1 & 0 & 0 & 0 & 0 & 1 & 0 & 1 & 0 \\
a & $p_{7}$ & 1 & 0 & 1 & 0 & 0 & 1 & 0 & 0 & 0 & 0 & 1 & 0 & 1 & 0 \\
b & $p_{8}$ & 1 & 0 & 0 & 1 & 1 & 0 & 0 & 0 & 0 & 0 & 1 & 0 & 1 & 0 \\
mrb & $p_{9}$ & 1 & 0 & 1 & 0 & 0 & 0 & 0 & 1 & 0 & 0 & 0 & 1 & 1 & 0 \\
\hline
\end{tabular}

Choosing the independent equations from the columns in the table above along with the requirement that the endmembers sum up to one gives:

$$
\begin{aligned}
& 1=p_{1}+p_{2}+p_{3}+p_{4}+p_{5}+p_{6}+p_{7}+p_{8}+p_{9} \\
& z_{1}=p_{1}+p_{2}+p_{4}+p_{5}+p_{6}+p_{7}+p_{8}+p_{9} \\
& z_{3}=p_{1}+p_{2}+p_{3}+p_{4}+p_{5}+p_{7}+p_{9} \\
& z_{5}=p_{1}+\frac{1}{2} p_{3}+p_{5}+p_{8} \\
& z_{6}=p_{6}+p_{7} \\
& z_{7}=p_{2}+\frac{1}{2} p_{3}+p_{4} \\
& z_{9}=p_{1}+p_{2}+p_{3} \\
& z_{10}=p_{5} \\
& z_{11}=p_{6}+p_{7}+p_{8}
\end{aligned}
$$

Solving for $p$ gives:

$$
\begin{aligned}
& p_{1}=\frac{1}{2} z_{1}+z_{5}+z_{6}-z_{10}-z_{11}-\frac{1}{2} \\
& p_{2}=\frac{1}{2} z_{1}-z_{5}-z_{6}+z_{9}+z_{10}+z_{11}-\frac{1}{2} \\
& p_{3}=1-z_{1} \\
& p_{4}=z_{5}+z_{6}+z_{7}-z_{9}-z_{10}-z_{11} \\
& p_{5}=z_{10} \\
& p_{6}=1-z_{3}+z_{6}-z_{11} \\
& p_{7}=z_{3}+z_{11}-1 \\
& p_{8}=-z_{6}+z_{11} \\
& p_{9}=1-z_{5}-z_{6}-z_{7}
\end{aligned}
$$

\section{Appendix 3: Pressure constraints example}

As an example, here the equations for the pressure constraints in a system with three different pressures, three phases and three compositions are spelled out.

The pressure constraints:

$$
\begin{aligned}
& \alpha_{1}^{1}+\alpha_{2}^{1}+\alpha_{3}^{1}=\pi_{\mathrm{sys}}^{1} \\
& \alpha_{1}^{2}+\alpha_{2}^{2}+\alpha_{3}^{2}=\pi_{\mathrm{sys}}^{2} \\
& \alpha_{1}^{3}+\alpha_{2}^{3}+\alpha_{3}^{3}=\pi_{\mathrm{sys}}^{3}
\end{aligned}
$$


The Gibbs energy function is to be minimized:

$$
\begin{aligned}
g_{\text {sys }}= & \left.\alpha_{1}^{1} g_{1}\right|_{P_{1}}+\left.\alpha_{2}^{1} g_{2}\right|_{P_{1}}+\left.\alpha_{3}^{1} g_{3}\right|_{P_{1}}+\left.\alpha_{1}^{2} g_{1}\right|_{P_{2}}+\left.\alpha_{2}^{2} g_{2}\right|_{P_{2}} \\
& +\left.\alpha_{3}^{2} g_{3}\right|_{P_{2}}+\left.\alpha_{1}^{3} g_{1}\right|_{P_{3}}+\left.\alpha_{2}^{3} g_{2}\right|_{P_{3}}+\left.\alpha_{3}^{3} g_{3}\right|_{P_{3}}
\end{aligned}
$$

The system composition constraints look similar to Eq. 44, for example, in case of having a component $x^{\mathrm{CaO}}$ :

$$
\begin{aligned}
x_{\mathrm{sys}}^{\mathrm{CaO}}= & \alpha_{1}^{1} x_{1}^{\mathrm{CaO}}+\alpha_{2}^{1} x_{2}^{\mathrm{CaO}}+\alpha_{3}^{1} x_{3}^{\mathrm{CaO}}+\alpha_{1}^{2} x_{1}^{\mathrm{CaO}} \\
& +\alpha_{2}^{2} x_{2}^{\mathrm{CaO}}+\alpha_{3}^{2} x_{3}^{\mathrm{CaO}}+\alpha_{1}^{3} x_{1}^{\mathrm{CaO}}+\alpha_{2}^{3} x_{2}^{\mathrm{CaO}}+\alpha_{3}^{3} x_{3}^{\mathrm{CaO}}
\end{aligned}
$$

For MATLAB, the constraint equations are written in matrix form resulting in:

$$
\left[\begin{array}{ccccccccc}
x_{1}^{\mathrm{SiO}_{2}} & x_{2} \mathrm{SiO}_{2} & x_{3}^{\mathrm{SiO}_{2}} & x_{1}^{\mathrm{SiO}_{2}} & x_{2}^{\mathrm{SiO}_{2}} & x_{3}^{\mathrm{SiO}_{2}} & x_{1}^{\mathrm{SiO}_{2}} & x_{2}^{\mathrm{SiO}_{2}} & x_{3}^{\mathrm{SiO}_{2}} \\
x_{1}^{\mathrm{CaO}} & x_{2}^{\mathrm{CaO}} & x_{3}^{\mathrm{CaO}} & x_{1}^{\mathrm{CaO}} & x_{2}^{\mathrm{CaO}} & x_{3}^{\mathrm{CaO}} & x_{1}^{\mathrm{CaO}} & x_{2}^{\mathrm{CaO}} & x_{3}^{\mathrm{CaO}} \\
x_{1}^{\mathrm{Al}_{2} \mathrm{O}_{3}} & x_{2}^{\mathrm{Al}_{2} \mathrm{O}_{3}} & x_{3}^{\mathrm{Al}_{2} \mathrm{O}_{3}} & x_{1}^{\mathrm{Al}_{2} \mathrm{O}_{3}} & x_{2}^{\mathrm{Al}_{2} \mathrm{O}_{3}} & x_{3}^{\mathrm{Al}_{2} \mathrm{O}_{3}} & x_{1}^{\mathrm{Al}_{2} \mathrm{O}_{3}} & x_{2}^{\mathrm{Al}_{2} \mathrm{O}_{3}} & x_{3}^{\mathrm{Al}_{2} \mathrm{O}_{3}} \\
1 & 1 & 1 & 0 & 0 & 0 & 0 & 0 & 0 \\
0 & 0 & 0 & 1 & 1 & 1 & 0 & 0 & 0 \\
0 & 0 & 0 & 0 & 0 & 0 & 1 & 1 & 1 \\
1 & 1 & 1 & 1 & 1 & 1 & 1 & 1 & 1
\end{array}\right]\left[\begin{array}{c}
\alpha_{1}^{1} \\
\alpha_{2}^{1} \\
\alpha_{3}^{1} \\
\alpha_{1}^{2} \\
\alpha_{2}^{2} \\
\alpha_{3}^{2} \\
\alpha_{1}^{3} \\
\alpha_{2}^{3} \\
\alpha_{3}^{3}
\end{array}\right]=\left[\begin{array}{c}
x_{\mathrm{sys}}^{\mathrm{SiO}_{2}} \\
x_{\text {sys }}^{\mathrm{CaO}} \\
x_{\mathrm{sys}} \\
\pi_{\text {sys }} \\
\pi_{\text {sys }}^{2} \\
\pi_{\text {sys }}^{3} \\
1
\end{array}\right]
$$

The optimization algorithm (function linprog in MATLAB) then searches for the alpha's between 0 and 1 that gives the minimum of Eq. 44 satisfying the equality matrix in Eq. 46. See Appendix 4 for code examples.

\section{Appendix 4: Code examples}

Code for standard $\mathrm{P}-T$ diagram calculation:

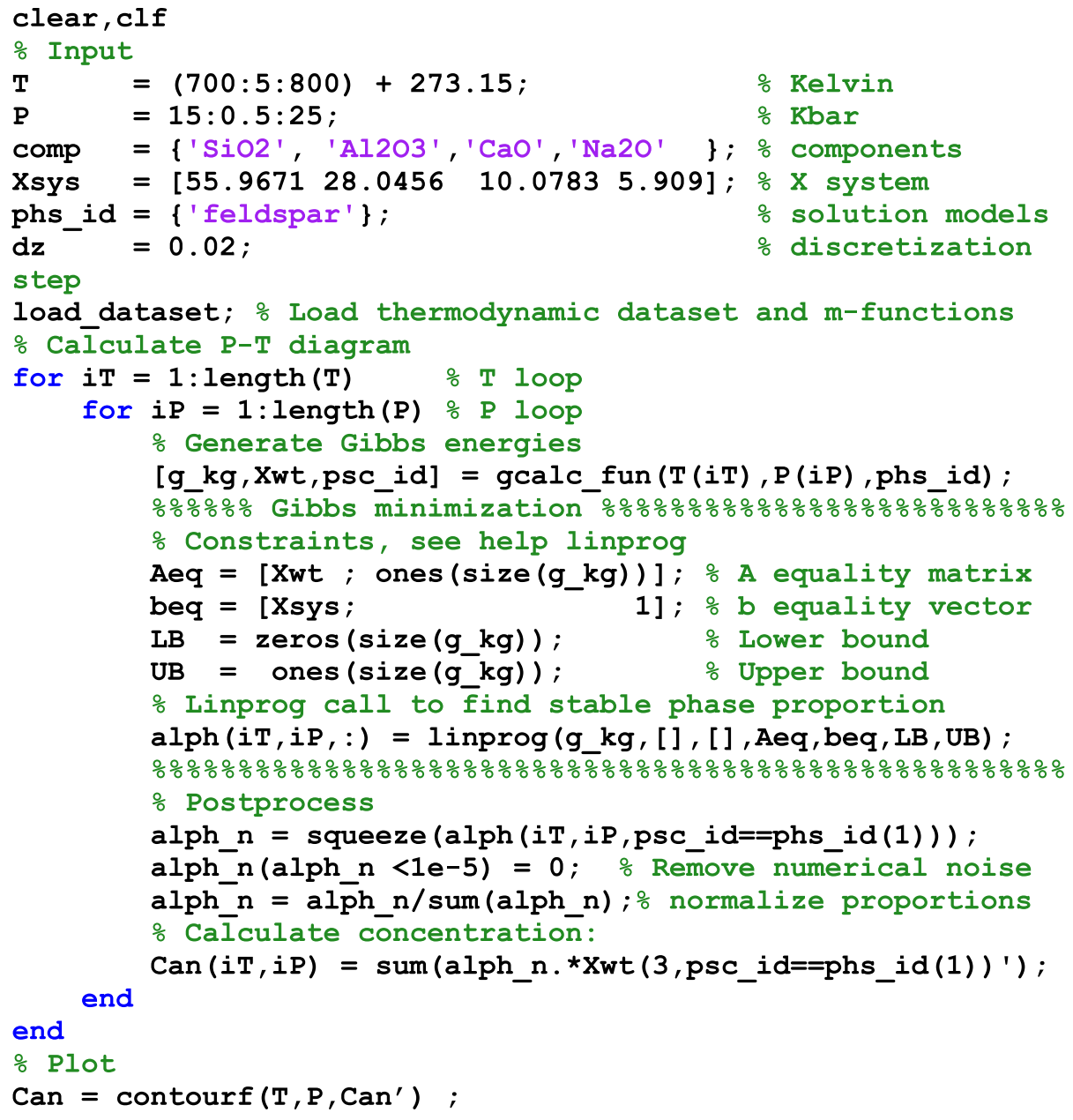


An example code to do minimization in presence of a pressure gradient:

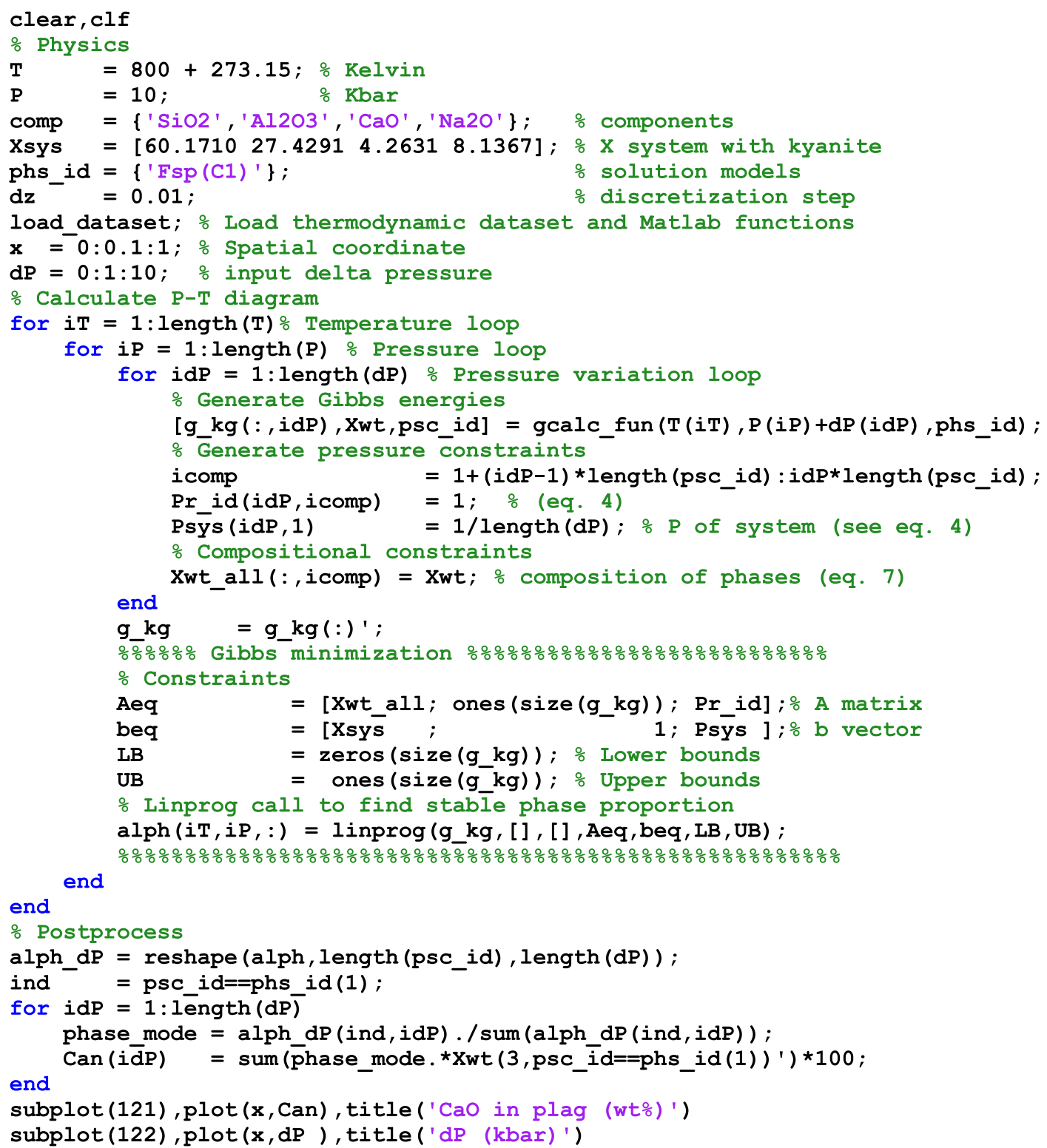

\section{References}

Andersen T, Austrheim H, Burke EAJ (1991) Fluid-induced retrogression of granulites in the Bergen Arcs, Caledonides of W. Norway: fluid inclusion evidence from amphibolite-facies shear zones. Lithos 27:29-42. doi:10.1016/0024-4937(91)90018-G

Ashworth JR, Birdi JJ, Emmett TF (1992) Diffusion in coronas around clinopyroxene: modeling with local equilibrium and steady-state, and a non-steady-state modification to account for zoned actinolite-hornblende. Contrib Mineral Petrol 109:307-325

Austrheim H, Griffin WL (1985) Shear deformation and eclogite formation within granulite-facies anorthosites of the Bergen Arcs, Western Norway. Chem Geol 50:267-281

Baldwin JA, Powell R, Williams ML, Goncalves P (2007) Formation of eclogite, and reaction during exhumation to mid-crustal levels, Snowbird tectonic zone, western Canadian Shield. J Metamorph Geol 25:953-974. doi:10.1111/j.1525-1314.2007.00737.x
Barron L (2005) A linear model and topology for the host-inclusion mineral system involving diamond. Can Mineral 43:203-224

Bohlen SR, Wall VJ, Boettcher AL (1983) Experimental investigations and geological applications of equilibria in the system $\mathrm{FeO}-\mathrm{TiO}$ (sub 2) - $\mathrm{Al}$ (sub 2) $\mathrm{O}$ (sub 3) - $\mathrm{SiO}$ (sub 2) - $\mathrm{H}$ (sub 2) O. Am Mineral 68:1049-1058

Brey GP, Köhler T (1990) Geothermobarometry in four-phase lherzolites II. New thermobarometers, and practical assessment of existing thermobarometers. J Petrol 31:1353-1378

Burnley PC (2013) The importance of stress percolation patterns in rocks and other polycrystalline materials. Nat Commun. doi: $10.1038 /$ ncomms 3117

Caddick MJ, Konopasek J, Thompson AB (2010) Preservation of garnet growth zoning and the duration of prograde metamorphism. J Petrol 51:2327-2347. doi:10.1093/petrology/egq059

Carswell DA, Harley SL (1990) Mineral barometry and thermometry. In: Carswell DA (ed) Eclogite facies rocks. Blackie, Glasgow, pp $83-110$ 
Carswell DA, Tucker RD, O'Brien PJ, Krogh TE (2003) Coesite microinclusions and the $\mathrm{U} / \mathrm{Pb}$ age of zircons from the Hareidland eclogite in the Western Gneiss Region of Norway. Lithos 67:181-190

Chopin C (1984) Coesite and pure pyrope in high-grade blueschists of the Western Alps: a 1st record and some consequences. Contrib Mineral Petrol 86:107-118

Chopin C (2003) Ultrahigh-pressure metamorphism: tracing continental crust into the mantle. Earth Planet Sci Lett 212:1-14

Coggon R, Holland TJB (2002) Mixing properties of phengitic micas and revised garnet-phengite thermobarometers. J Metamorph Geol 20:683-696. doi:10.1046/j.1525-1314.2002.00395.x

Connolly JAD (2005) Computation of phase equilibria by linear programming: a tool for geodynamic modeling and its application to subduction zone decarbonation. Earth Planet Sci Lett 236:524541. doi:10.1016/j.epsl.2005.04.033

Dale J, Powell R, White RW et al (2005) A thermodynamic model for $\mathrm{Ca}-\mathrm{Na}$ clinoamphiboles in $\mathrm{Na} 2 \mathrm{O}-\mathrm{CaO}-\mathrm{FeO}-\mathrm{MgO}-\mathrm{Al} 2 \mathrm{O} 3$ $\mathrm{SiO} 2-\mathrm{H} 2 \mathrm{O}-\mathrm{O}$ for petrological calculations. J Metamorph Geol 23:771-791. doi:10.1111/j.1525-1314.2005.00609.x

Diener JFA, Powell R, White RW, Holland TJB (2007) A new thermodynamic model for clino- and orthoamphiboles in the system $\mathrm{Na} 2 \mathrm{O}-\mathrm{CaO}-\mathrm{FeO}-\mathrm{MgO}-\mathrm{A} 12 \mathrm{O} 3-\mathrm{SiO} 2-\mathrm{H} 2 \mathrm{O}-\mathrm{O}$. J Metamorph Geol 25:631-656

Enami M, Nishiyama T, Mouri T (2007) Laser Raman microspectrometry of metamorphic quartz: a simple method for comparison of metamorphic pressures. Am Mineral 92:1303-1315. doi:10.2138/am.2007.2438

Esposito RO, Castier M, Tavares FW (2000) Calculations of thermodynamic equilibrium in systems subject to gravitational fields. Chem Eng Sci 55:3495-3504. doi:10.1016/S0009-2509(00)00010-5

Fuhrman ML, Lindsley DH (1988) Ternary-feldspar modeling and thermometry. Am Mineral 73:201-215

Gaidies F, de Capitani C, Abart R (2008) THERIA_G: a software program to numerically model prograde garnet growth. Contrib Mineral Petrol 155:657-671. doi:10.1007/s00410-007-0263-Z

Gibbs JW (1906) The scientific papers: thermodynamics. Longmans, Green and co., London

Gillet P, Ingrin J, Chopin C (1984) Coesite in subducted continentalcrust: P-T history deduced from an elastic model. Earth Planet Sci Lett 70:426-436

Griffin WL (1971) Genesis of coronas in anorthosites of Upper Jotun Nappe, Indre-Sogn, Norway. J Petrol 12:219-243

Guiraud M, Powell R (2006) P-V-T relationships and mineral equilibria in inclusions in minerals. Earth Planet Sci Lett 244:683-694

Holland TJB, Powell R (1990) An enlarged and updated internally consistent thermodynamic dataset with uncertainties and correlations: the system $\mathrm{K} 2 \mathrm{O}-\mathrm{Na} 2 \mathrm{O}-\mathrm{CaO}-\mathrm{MgO}-\mathrm{MnO}-\mathrm{FeO}-$ $\mathrm{Fe} 2 \mathrm{O} 3-\mathrm{A} 12 \mathrm{O} 3-\mathrm{TiO} 2-\mathrm{SiO} 2-\mathrm{C}-\mathrm{H} 2-\mathrm{O} 2 . \quad \mathrm{J}$ Metamorph Geol 8:89-124

Holland T, Powell R (1992) Plagioclase feldspars: activity-composition relations based upon Darken quadratic formalism and Landau theory. Am Mineral 77:53-61

Holland T, Powell R (1996) Thermodynamics of order-disorder in minerals.2. Symmetric formalism applied to solid solutions. Am Mineral 81:1425-1437

Holland TJB, Powell R (1998) An internally consistent thermodynamic data set for phases of petrological interest. J Metamorph Geol 16:309-343

Holland T, Powell R (2003) Activity-composition relations for phases in petrological calculations: an asymmetric multicomponent formulation. Contrib Mineral Petrol 145:492-501

Hwang SL, Shen P, Yui TF, Chu HT (2007) TiO2 nanoparticle trails in garnet: implications of inclusion pressure-induced microcracks and spontaneous metamorphic-reaction healing during exhumation. J Metamorph Geol 25:451-460. doi:10.1111/j.1525-1314.2007.00705.x
Kenkmann T, Dresen G (1998) Stress gradients around porphyroclasts; palaeopiezometric estimates and numerical modelling. Struct Prop High Strain Zones Rocks 20:163-173

Kohn MJ (2014) “Thermoba-Raman-try": calibration of spectroscopic barometers and thermometers for mineral inclusions. Earth Planet Sci Lett 388:187-196. doi:10.1016/j.epsl.2013.11.054

Korzhinskii DS (1970) Theory of metasomatic zoning. Clarendon Press, Oxford

Koukkari P, Pajarre R (2011) A Gibbs energy minimization method for constrained and partial equilibria. Pure Appl Chem 83:12431254. doi:10.1351/Pac-Con-10-09-36

Krogh TE, Kamo SL, Robinson P et al (2011) U-Pb zircon geochronology of eclogites from the Scandian Orogen, northern Western Gneiss region, Norway; 14-20 million years between ecologite crystallization and return to amphibolite-facies conditions. Can J Earth Sci Rev Can Sci Terre 48:441-472. doi:10.1139/E10-076

Lanari P, Vidal O, De Andrade V et al (2014) XMapTools: A MATLAB (c)-based program for electron microprobe X-ray image processing and geothermobarometry. Comput Geosci 62:227240. doi:10.1016/j.cageo.2013.08.010

Landau LD, Lifshitz EM (1987) Fluid mechanics, 2nd edn. Butterworth Heinemann, Oxford, UK

Llana-Funez S, Wheeler J, Faulkner DR (2012) Metamorphic reaction rate controlled by fluid pressure not confining pressure: implications of dehydration experiments with gypsum. Contrib Mineral Petrol 164:69-79. doi:10.1007/s00410-012-0726-8

Macgregor ID (1974) The system MgO-Al2O3-SiO2: solubility of $\mathrm{A} 12 \mathrm{O} 3$ in enstatite for spinel and garnet peridotite compositions. Am Mineral 59:110-119

Mancktelow NS (2008) Tectonic pressure: theoretical concepts and modelled examples. Lithos 103:149-177. doi:10.1016/j. lithos.2007.09.013

Martins LSF, Tavares FW, Pecanha RP, Castier M (2005) Centrifugation equilibrium for spheres and spherocylinders. J Colloid Interface Sci 281:360-367. doi:10.1016/j.jcis.2004.08.106

McFarlane CRM, Carlson WD, Connelly JN (2003) Prograde, peak, and retrograde $\mathrm{P}-\mathrm{T}$ paths from aluminium in orthopyroxene: high-temperature contact metamorphism in the aureole of the Makhavinekh Lake Pluton, Nain Plutonic Suite, Labrador. J Metamorph Geol 21:405-423. doi:10.1046/j.1525-1314.2003.00446.x

Milke R, Abart R, Kunze K et al (2009) Matrix rheology effects on reaction rim growth I: evidence from orthopyroxene rim growth experiments. J Metamorph Geol 27:71-82. doi:10.1111/j.1525-1314.2008.00804.x

Miller DG (1956) Thermodynamic theory of irreversible processes. II. Sedimentation equilibrium of fluids in gravitational and centrifugal fields. Am J Phys 24:555-561. doi:10.1119/1.1934319

Misra S, Mandal N (2007) Localization of plastic zones in rocks around rigid inclusions; insights from experimental and theoretical models. J Geophys Res. doi:10.1029/2006JB004328

Mosenfelder JL, Bohlen SR (1997) Kinetics of the coesite to quartz transformation. Earth Planet Sci Lett 153:133-147

Moulas E, Podladchikov YY, Aranovich LY, Kostopoulos D (2013) The problem of depth in geology: When pressure does not translate into depth. Petrology 21:527-538. doi:10.1134/ S0869591113060052

Moulas E, Burg J-P, Podladchikov Y (2014) Stress field associated with elliptical inclusions in a deforming matrix: mathematical model and implications for tectonic overpressure in the lithosphere. Obs Model Perspect Mech Prop Lithosphere 631:37-49. doi:10.1016/j.tecto.2014.05.004

Mueller I, Weiss W (2012) Thermodynamics of irreversible processes-past and present. Eur Phys J H 37:139-236. doi:10.1140/epjh/e2012-20029-1

Mukai H, Austrheim HO, Putnis CV, Putnis A (2014) Textural evolution of plagioclase feldspar across a shear zone; implications 
for deformation mechanism and rock strength. J Petrol 55:14571477. doi:10.1093/petrology/egu030

Nimis P, Grutter H (2010) Internally consistent geothermometers for garnet peridotites and pyroxenites. Contrib Mineral Petrol 159:411-427. doi:10.1007/s00410-009-0455-9

O'Brien PJ, Ziemann MA (2008) Preservation of coesite in exhumed eclogite: insights from Raman mapping. Eur $J$ Mineral 20:827-834

Parkinson CD (2000) Coesite inclusions and prograde compositional zonation of garnet in whiteschist of the HP-UHPM Kokchetav massif, Kazakhstan: a record of progressive UHP metamorphism. Lithos 52:215-233

Parkinson CD, Katayama I (1999) Present-day ultrahigh-pressure conditions of coesite inclusions in zircon and garnet; evidence from laser Raman microspectroscopy. Geol Boulder 27:979-982. doi:10.1130/0091-7613(1999)027<0979:PDUPCO>2.3.CO;2

Perrillat JP, Daniel I, Lardeaux JM, Cardon H (2003) Kinetics of the coesite-quartz transition: application to the exhumation of ultrahigh-pressure rocks. J Petrol 44:773-788

Powell R (1987) Darken quadratic formalism and the thermodynamics of minerals. Am Mineral 72:1-11

Powell R, Holland T (1993) On the formulation of simple mixing models for complex phases. Am Mineral 78:1174-1180

Pryer LL, Robin P-YF (1996) Differential stress control on the growth and orientation of flame perthite: a palaeostress-direction indicator. J Struct Geol 18:1151-1166. doi:10.1016/0191-8141(96)00037-5

Ravna-Krogh EJ, Paquin J (2003) Thermobarometric methodologies applicable to eclogites and garnet ultrabasites. In: Carswell DA, Compagnoni R (eds) Metamorph. Ultrah. Press., Eötvös University Press, Budapest, pp 229-259

Robin P-YF (1974) Stress and strain in cryptoperthite lamellae and the coherent solvus of alkali feldspars. Am Mineral 59:1299-1318

Savenko SV, Dijkstra M (2004) Sedimentation and multiphase equilibria in suspensions of colloidal hard rods. Phys Rev E 70:051401. doi:10.1103/PhysRevE.70.051401

Schmid DW (2005) Rigid polygons in shear. High-Strain Zones Struct Phys Prop 245:421-431

Schmid DW, Podladchikov YY (2003) Analytical solutions for deformable elliptical inclusions in general shear. Geophys J Int 155:269-288

Schmid DW, Abart R, Podladchikov YY, Milke R (2009) Matrix rheology effects on reaction rim growth II: coupled diffusion and creep model. J Metamorph Geol 27:83-91

Schmidt C, Ziemann MA (2000) In-situ Raman spectroscopy of quartz; a pressure sensor for hydrothermal diamond-anvil cell experiments at elevated temperatures. Am Mineral 85:1725-1734

Schrank CE, Fusseis F, Karrech A, Regenauer-Lieb K (2012) Thermal-elastic stresses and the criticality of the continental crust. Geochem Geophys Geosyst. doi:10.1029/2012GC004085

Simpson C, Wintsch RP (1989) Evidence for deformation-induced K-feldspar replacement by myrmekite. J Metamorph Geol 7:261-275

Smith DC (1984) Coesite in clinopyroxene in the Caledonides and its implications for geodynamics. Nature 310:641-644

Smith D, Barron BR (1991) Pyroxene-garnet equilibration during cooling in the mantle. Am Mineral 76:1950-1963

Spear FS (1993) Metamorphic phase equilibria and pressure-temperature-time paths. Mineralogical Society of America, Washington, $799 \mathrm{pp}$

Spear FS, Selverstone J (1983) Quantitative P-T paths from zoned minerals: theory and tectonic applications. Contrib Mineral Petrol 83:348-357
Stipska P, Powell R, White RW, Baldwin JA (2010) Using calculated chemical potential relationships to account for coronas around kyanite: an example from the Bohemian Massif. J Metamorph Geol 28:97-116. doi:10.1111/j.1525-1314.2009.00857.x

Tajčmanová L, Connolly JAD, Cesare B (2009) A thermodynamic model for titanium and ferric iron solution in biotite. J Metamorph Geol 27:153-165. doi:10.1111/j.1525-1314.2008.00812.x

Tajčmanová L, Abart R, Neusser G, Rhede D (2011) Growth of plagioclase rims around metastable kyanite during decompression of high-pressure felsic granulites (Bohemian Massif). J Metamorph Geol 29:1003-1018. doi:10.1111/j.1525-1314.2011.00953.x

Tajčmanová L, Podladchikov Y, Powell R et al (2014) Grain-scale pressure variations and chemical equilibrium in high-grade metamorphic rocks. J Metamorph Geol 32:195-207. doi:10.1111/ jmg. 12066

Tajčmanová L, Vrijmoed J, Moulas E (2015) Grain-scale pressure variations in metamorphic rocks: implications for the interpretation of petrographic observations. Lithos 216-217:338-351. doi:10.1016/j.lithos.2015.01.006

Tenczer V, Stuewe K, Barr TD (2001) Pressure anomalies around cylindrical objects in simple shear. J Struct Geol 23:777-788

Van der Molen I, van Roermund HLM (1986) The pressure path of solid inclusions in minerals: the retention of coesite inclusions during uplift. Lithos 19:317-324

Vrijmoed JC, Hacker BR (2014) Determining P-T paths from garnet zoning using a brute-force computational method. Contrib Mineral Petrol 167:1-13. doi:10.1007/s00410-014-0997-3

Vrijmoed JC, Van Roermund HLM, Davies GR (2006) Evidence for diamond-grade ultra-high pressure metamorphism and fluid interaction in the Svartberget Fe-Ti garnet peridotite-websterite body, Western Gneiss Region, Norway. Mineral Petrol 88:381-405

Vrijmoed JC, Smith DC, van Roermund HLM (2008) Raman confirmation of microdiamond in the Svartberget Fe-Ti type garnet peridotite, Western Gneiss Region, Western Norway. Terra Nova 20:295-301

Vrijmoed JC, Podladchikov YY, Andersen TB, Hartz EH (2009) An alternative model for ultra-high pressure in the Svartberget Fe-Ti garnet-peridotite, Western Gneiss Region, Norway. Eur J Mineral 21:1119-1133. doi:10.1127/0935-1221/2009/0021-1985

Vrijmoed JC, Austrheim H, John T et al (2013) Metasomatism of the ultra-high pressure Svartberget Fe-Ti type garnet-peridotite, Western Gneiss Region, Norway. J Petrol 54:1815-1848. doi:10.1093/petrology/egt032

Wensink HH, Lekkerkerker HNW (2004) Sedimentation and multiphase equilibria in mixtures of platelets and ideal polymer. Europhys Lett 66:125-131. doi:10.1209/epl/i2003-10140-1

White RW, Powell R, Holland TJB (2007) Progress relating to calculation of partial melting equilibria for metapelites. J Metamorph Geol 25:511-527

Will TM, Powell R (1992) Activity-composition relationships in multicomponent amphiboles: an application of darken quadratic formalism. Am Mineral 77:954-966

Wood BJ (1974) Solubility of alumina in orthopyroxene coexisting with garnet. Contrib Mineral Petrol 46:1-15

Ye K, Liou JB, Cong B, Maruyama S (2001) Overpressures induced by coesite-quartz transition in zircon. Am Mineral 86:1151-1155

Young TF, Kraus KA, Johnson JS (1954) Thermodynamics of equilibrium in the ultracentrifuge. J Chem Phys 22:878-880

Zhang Y (1998a) Mechanical and phase equilibria in inclusion-host systems. Earth Planet Sci Lett 157:209-222

Zhang Y (1998b) Solving large-scale linear programs by interiorpoint methods under the MATLAB environment. Optim Methods Softw 10:1-31. doi:10.1080/10556789808805699 